\title{
Converging preganglionic axons refine without synaptic transmission when targets downstream of sympathetic nerves are active
}

\author{
Yumaine Chong ${ }^{1,2}$, Ellis Cooper ${ }^{1,2 *}$.
}

\section{Affiliations:}

1Department of Physiology, McGill University, Montréal, Québec, Canada. 2Integrated Program in Neuroscience, McGill University, Montréal, Québec, Canada. *Corresponding author/Lead contact: ellis.cooper@mcgill.ca.

Abstract:

It is well accepted that refinement of converging presynaptic inputs depends on postsynaptic activity; however, it remains unclear how this developmental event is initiated. To address this, we developed a mosaic model where synaptically-active and synaptically-inactive sympathetic neurons develop side-by-side in the same ganglion.

15 Surprisingly, we show that converging presynaptic inputs refine on neurons even without synaptic transmission as long as the synaptically-silent neurons share targets with synaptically-active neurons. In addition, our single-cell RNA sequencing experiments show that sympathetic ganglia contain at least 7 neuronal subtypes that decode the impact of synaptic activity differently, including their ability to maintain an adrenergic phenotype.

20 Our results provide a new view on the roles that synaptic transmission and retrograde target activity have on developing circuits.

\section{Introduction:}

When developing neural circuits start to form, the resulting synaptic activity plays a crucial role in shaping the patterns of connections as these circuits refine and mature. A common approach to demonstrate synaptic activity's influence is to block synaptic transmission, either pharmacologically or genetically, in specific pathways and examine the consequences on circuit development. Such studies have provided valuable cellular and molecular data on how postsynaptic neurons respond when synaptic activity is blocked (Buffelli et al., 2003; Cohen-Cory, 2002; Flavell and Greenberg, 2008; Hua and Smith, 2004; Redmond, 2008; Thompson et al., 1979; Wong and Ghosh, 2002). In many of these studies, however, the loss of synaptic activity in postsynaptic neurons also reduces the activity of their targets, making it difficult to resolve whether differences in morphology, input convergence, or gene expression are caused by a direct block of synaptic transmission on the postsynaptic neuron, or whether they result from the absence of non-cell autonomous factors, such as a reduction in activity-dependent factors emanating from the neuron's targets, or some combination of the two (da Silva and Wang, 2011; Yamashita and Kuruvilla, 2016). Therefore, the interpretation of activity's role in circuit development can be problematic, and despite much progress, more work is needed to understand fully the multiple influences that synaptic activity exerts during development. 
We are mainly interested in the developmental refinement of converging inputs, a process that depends critically on synaptic activity. The general consensus is that refinement of synaptic connections is a competitive process: converging inputs compete for molecules secreted from postsynaptic neurons; the successful inputs persist and are strengthened, and less successful ones are eliminated (Balice-Gordon and Lichtman, 1994; Chong et al., 2018; Hashimoto et al., 2011; Kawata et al., 2014; Lorenzetto et al., 2009). A number of molecules have been shown to play a role in eliminating unwanted or inappropriate connections. Yet, there is much about the molecular mechanisms that underlie the refinement of inputs that remains poorly understood. Fundamental, unresolved questions are: How does synaptic activity instruct inputs to refine, and where do these activitydependent signals originate?

Mice with a deletion in the alpha 3 nicotinic acetylcholine receptor ( $\mathrm{AAChR}$ ) subunit gene ( $\alpha 3 \mathrm{KO}$ ) are attractive models to investigate these questions. Alpha 3-containing nAChRs are the major postsynaptic receptors at synapses between preganglionic nerve terminals and sympathetic neurons, and $\alpha 3 \mathrm{KO}$ mice have no fast-synaptic transmission in sympathetic ganglia, although presynaptic terminals from preganglionic axons establish morphological synapses that appear normal (Krishnaswamy and Cooper, 2009).

20 Sympathetic neurons are innervated by 8-10 preganglionic axons at birth and all but 1-3 inputs are eliminated by 1 month. In $\alpha 3$ KO SCG, however, preganglionic axons do not refine, and sympathetic neurons receive silent synapses from 8-10 preganglionic inputs (Chong et al., 2018). Synaptically-silent sympathetic neurons in $\alpha 3 \mathrm{KO}$ mice also have silent targets, raising the possibility that inputs do not refine on these neurons because of the

25 absence of non-cell autonomous target factors, rather than exclusively from the absence of nerve-evoked depolarizations of the postsynaptic neuron.

To address this issue, we established a model in which synaptically-silent neurons develop side-by-side with synaptically-active neurons and share innervation of common targets.

30 This was accomplished by genetically engineering mice to have mosaic sympathetic ganglia composed of two functionally different populations of sympathetic neurons. In these mice, half the neurons have a deletion in the $\alpha 3$ gene and do not have functional postsynaptic nAChRs; the other half, which are randomly intermingled with the first, express functional postsynaptic nAChRs. Importantly, the nAChR-expressing neurons are synaptically excited

35 by preganglionic neurons and can drive activity of downstream targets, whereas those without nAChRs are synaptically silent. Using these mosaic ganglia, we could investigate preganglionic innervation, as well as morphological differentiation, and gene expression profiles of neighboring sympathetic neurons that develop postnatally in vivo, either with or without synaptic transmission. 
Interestingly, we discovered that postsynaptic activity is not required for refinement of preganglionic inputs to sympathetic neurons in mosaic ganglia. Rather, our results show that preganglionic axons refine in the absence of synaptic transmission provided that the targets downstream of the postsynaptic sympathetic neurons are active.

In support of these conclusions, we conducted single-cell RNA sequencing (scRNAseq) on WT, $\alpha 3 \mathrm{KO}$, and mosaic SCG to quantify changes in gene expression in different subpopulations. SCG contains at least 7 neuronal subtypes, and we found that postsynaptic activity affects gene expression differently in these 7 subtypes. Over 240 genes were

10 differentially expressed between WT SCG neurons and synaptically-silent neurons from $\alpha 3$ KO SCG. Unexpectedly, we found a large increase in the number of neurons in synapticallysilent $\alpha 3$ KO SCG that expressed cholinergic genes, including the high affinity choline transporter, CHT, and the vesicular acetylcholine transporter, VAChT; this indicates that synaptic activity is required for sympathetic neurons to maintain an adrenergic phenotype.

15 Furthermore, of the 240 genes that were differentially expressed in $\alpha 3$ KO neurons, over 85 were expressed at near WT levels in synaptically-silent neurons in mosaic SCG, suggesting that retrograde target activity regulates the expression of these genes.

\section{Results:}

20 To investigate whether signal(s) that instruct inputs to refine originate at synaptic sites through a pathway directly triggered by postsynaptic activity, or originate elsewhere, we developed mosaic sympathetic ganglia where synaptically-silent neurons develop side-byside with synaptically-active neurons and share innervation of common targets. To create these mosaic ganglia, we engineered mice to express from the HPRT site on the X

25 chromosome either the nAChR subunit gene $\alpha 3$ (referred to as $\mathrm{X}^{\alpha 3}$ ), or the gene for mRFP1 (referred to as $\mathrm{X}^{\mathrm{RFP}}$ ), under the control of the human ubiquitin promoter. These mice were then mated to $\alpha 3 \mathrm{KO}$ mice (mice with a deletion in the endogenous $\alpha 3$ gene (Krishnaswamy and Cooper, 2009; Rassadi et al., 2005; Xu et al., 1999)). Due to random X-inactivation, the female progeny had mosaic sympathetic ganglia in which only neurons containing $\mathrm{X}^{\alpha 3}$

30 expressed functional nAChRs, whereas neurons containing $\mathrm{X}^{\mathrm{RFP}}$ had no nAChRs (Figures 1A and B; Figure S1). We recorded from hundreds of neurons in intact superior cervical ganglia (SCG) to demonstrate that only $\mathrm{X}^{\alpha 3}$ neurons were excited by preganglionic nerve stimulation (Figure 1C). Fast EPSPs on these $\mathrm{X}^{\alpha 3}$ neurons were indistinguishable from those on age-matched sympathetic neurons from WT mice. On the other hand, stimulating

35 the preganglionic nerve failed to evoke any detectable responses from $\mathrm{X}^{\mathrm{RFP}}$ neurons, although these $\mathrm{X}^{\mathrm{RFP}}$ neurons received morphological contacts (Figure S1) and were capable of generating overshooting action potentials with direct current injection (Figure 1D). 

(which was not certified by peer review) is the author/funder. All rights reserved. No reuse allowed without permission.
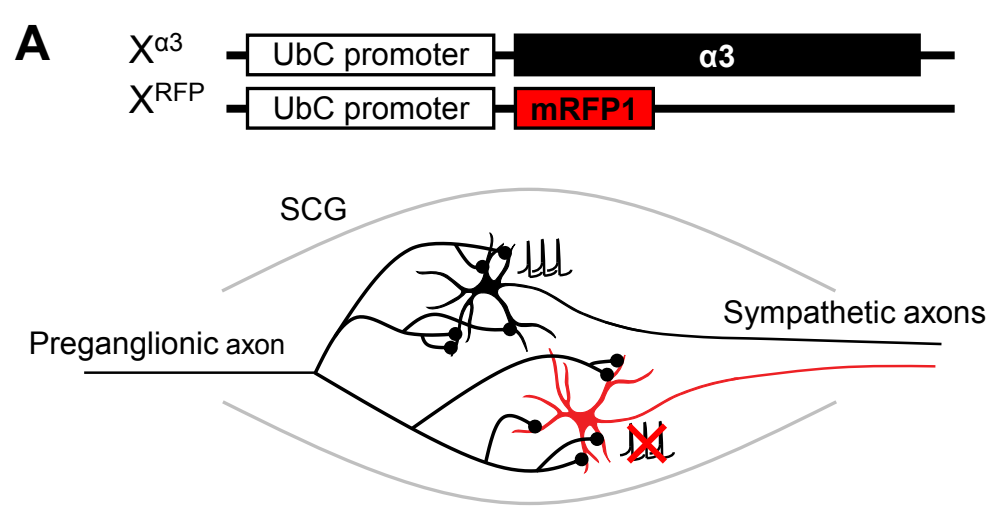

B

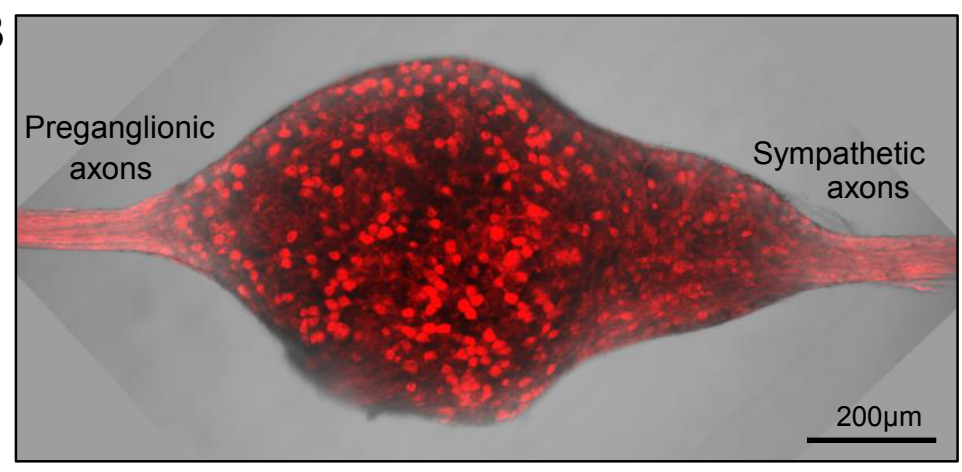

C

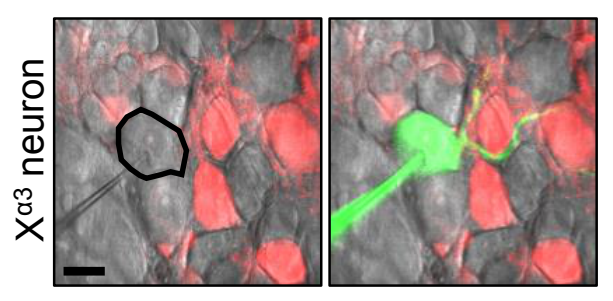

D

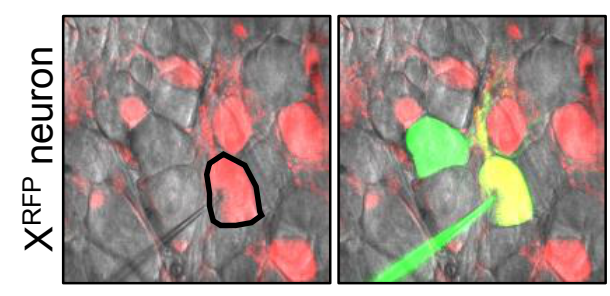

E $X^{\alpha 3} \mathrm{P} 7-8$
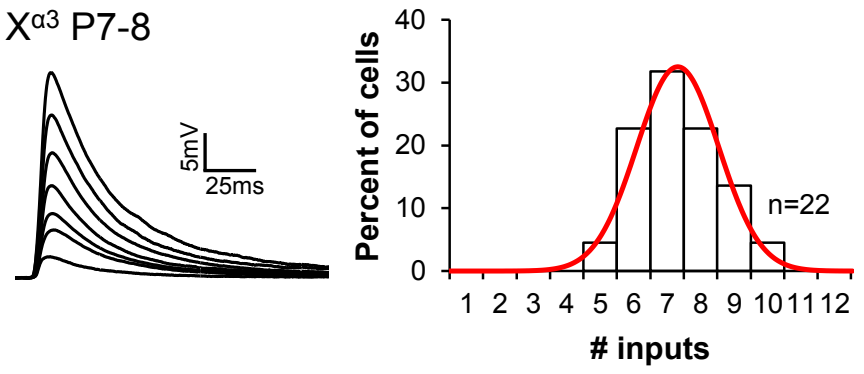

$F_{X^{a 3}} \mathrm{P}^{25-28}$
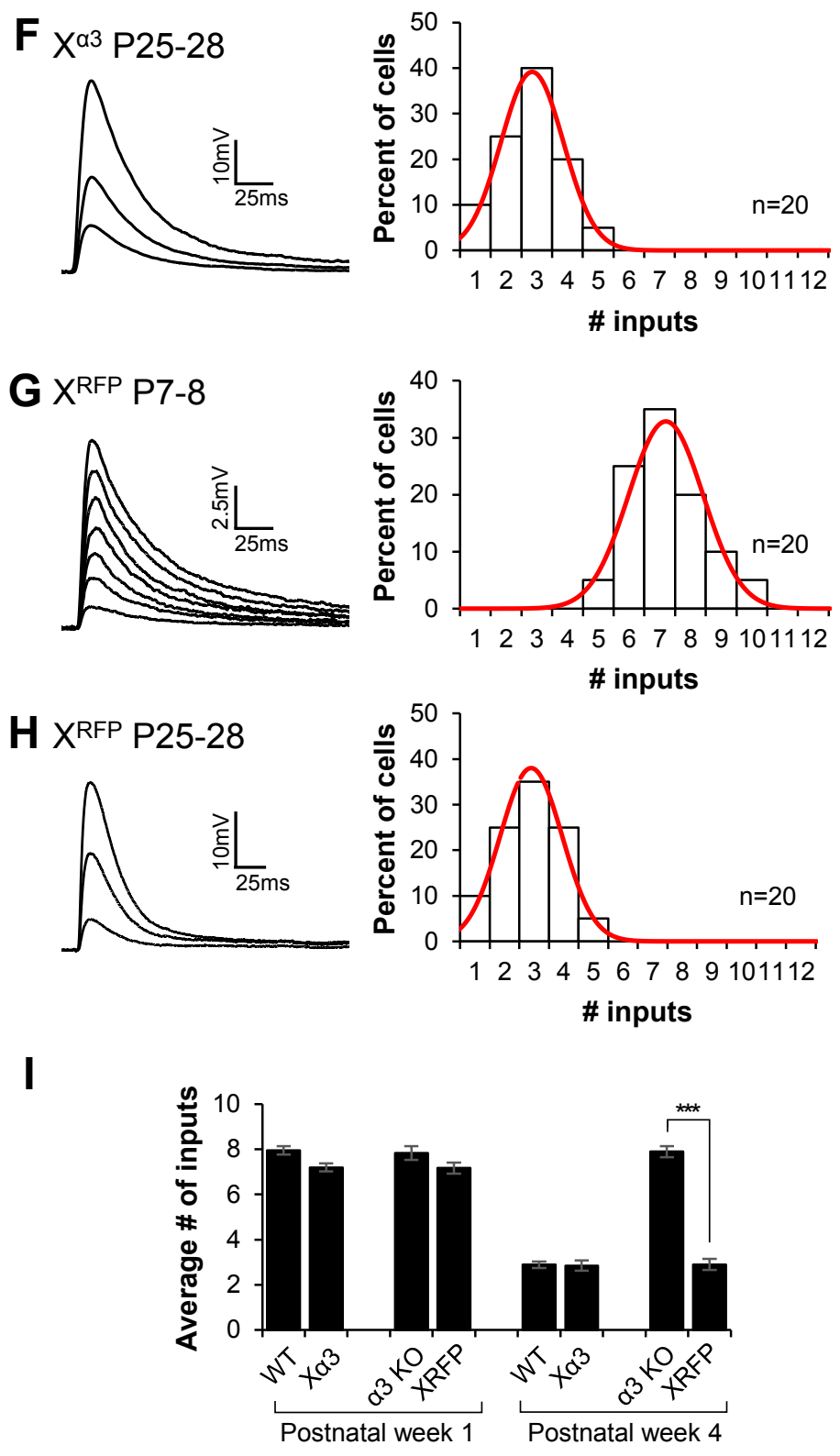
Figure 1. Random $X$ inactivation generates mosaic population of synaptically-active and inactive neurons in sympathetic ganglia.

(A) Schematic drawing of a mosaic SCG with a preganglionic axon innervating a neuron (black) with $\alpha 3$-containing nAChRs $\left(\mathrm{X}^{\alpha 3}\right)$ and a neuron (red) without $\mathrm{nAChRs}\left(\mathrm{X}^{\mathrm{RFP}}\right)$ that expresses RFP. See also Figure S1.

(B) Superimposed DIC and confocal images of an intact mosaic SCG composed of nonfluorescent $\mathrm{X}^{\alpha 3}$ neurons and RFP-expressing $\mathrm{X}^{\mathrm{RFP}}$ neurons. See also Figure S1.

(C, D) Superimposed DIC and confocal images (scale bar, 20 $\mu \mathrm{m}$ ) of an $\mathrm{X}^{\alpha 3}$ (C) and an $\mathrm{X}^{\mathrm{RFP}}$

(D) recorded intracellularly with a sharp electrode filled with Alexa Fluor 488 hydrazide

10 (green) and the corresponding electrophysiological response to preganglionic nerve stimulation (right). Preganglionic stimulation evokes suprathreshold EPSPs from $\mathrm{X}^{\alpha 3}$ neurons and no responses from $\mathrm{X}^{\mathrm{RFP}}$ neurons. Inset in $\mathrm{D}$ shows an action potential from a $\mathrm{X}^{\mathrm{RFP}}$ neuron evoked with current injection.

(E-H) Left: Representative EPSPs in a (E) P7-8 X ${ }^{\alpha 3}$ neuron, (F) P25-28 X ${ }^{\alpha 3}$ neuron, (G) P7-8

$15 \mathrm{X}^{\mathrm{RFP}}$ neuron, and (H) P25-28 $\mathrm{X}^{\mathrm{RFP}}$ neuron in mosaic SCG evoked by increasing stimuli to the preganglionic nerve.

Right: Distribution of SCG neurons innervated by the number of inputs, fit with a Gaussian function. Each distribution in E-H contains data from at least 8 mice; $n$ refers to the number of neurons.

20 (I) The average number of axons innervating WT neurons, $\alpha 3$ K0 neurons, $\mathrm{X}^{\alpha 3}$ neuron, and $\mathrm{X}^{\mathrm{RFP}}$ neurons at postnatal week 1 and 4. WT and $\alpha 3 \mathrm{KO}$ data are from Chong et al., 2018. Error bars represent $\pm \mathrm{SEM}$; ${ }^{* * *} \mathrm{p}<0.001$. 
Refinement is generally considered to be a competitive process in which the stronger inputs are maintained and strengthened, and weaker inputs are eliminated (Cohen-Cory, 2002; Kano and Hashimoto, 2009; Katz and Shatz, 1996; Lichtman and Colman, 2000; Zhang and Poo, 2001). Accordingly, one prediction is that during early postnatal development, a preganglionic axon in mosaic ganglia would maintain functional inputs on $\mathrm{X}^{\alpha 3}$ neurons and eliminate all silent contacts on $\mathrm{X}^{\mathrm{RFP}}$ neurons. To test this prediction, we measured EPSPs while gradually increasing the stimulus to the preganglionic nerve (Chong et al., 2018). To measure EPSPs on $\mathrm{X}^{\mathrm{RFP}}$ neurons, we unsilenced synapses by viral expression of $\alpha 3$ for one to two days prior to recording (Chong et al., 2018; Krishnaswamy

10 and Cooper, 2009). In addition, to confirm that we recorded from either an $\mathrm{X}^{\alpha 3}$ neuron or an $\mathrm{X}^{\mathrm{RFP}}$ neuron, we included an Alexa Fluor 488 dye in the recording electrode and imaged neurons with confocal microscopy during the recordings (Figures 1C and D).

Seven-8 days after birth, $\mathrm{X}^{\alpha 3}$ neurons were functionally innervated by 6-8 preganglionic

15 inputs, and by one month, most inputs were eliminated and only 1-3 remained (Figures 1E and F) similar to the refinement of preganglionic axons innervating SCG neurons in WT mice (Figure 1I) (Chong et al., 2018). $\mathrm{X}^{\mathrm{RFP}}$ neurons were also innervated by 6-8 preganglionic axons 7-8 days after birth (Figure 1G). Unexpectedly, however, by postnatal day 28 (P28), $\mathrm{X}^{\mathrm{RFP}}$ neurons were innervated by 1-3 preganglionic axons, the same number

20 innervating $\mathrm{X}^{\alpha 3}$ or WT neurons at P28 (Figures 1H and I). These data demonstrate that converging inputs to synaptically-silent $\mathrm{X}^{\mathrm{RFP}}$ neurons in mosaic SCG refined without postsynaptic activity. This is in direct contrast to those innervating synaptically-silent SCG neurons in $\alpha 3 \mathrm{KO}$ mice where converging preganglionic axons do not refine (Chong et al., 2018).

One possibility for this difference in the refinement of preganglionic inputs to $\alpha 3$ KO SCG neurons compared to those innervating $\mathrm{X}^{\mathrm{RFP}}$ neurons is that $\mathrm{X}^{\mathrm{RFP}}$ neurons benefit from activity-dependent factors released by their targets. In $\alpha 3 \mathrm{KO}$ mice, synaptic transmission in the SCG is completely abolished (Chong et al., 2018; Krishnaswamy and Cooper, 2009),

30 and the activities of targets innervated by autonomic neurons are substantially reduced (Xu et al., 1999); on the other hand, in mosaic SCG, these targets are functionally innervated by $\mathrm{X}^{\alpha 3}$ neurons. This difference may affect target innervation and possibly the convergence of preganglionic innervation (McAllister et al., 1999; Park and Poo, 2012; da Silva and Wang, 2011). Therefore, we quantified target innervation in WT, $\alpha 3 \mathrm{KO}$, and mosaic mice. As a

35 target, we focused on the radial muscles of the iris, a tissue that causes pupil dilation upon sympathetic nerve stimulation (Hill et al., 1991).

\section{Sympathetic innervation of the iris}

To quantify the number of SCG neurons that project to iris, we injected the retrograde 40 tracer, cholera toxin subunit B conjugated to Alexa Fluor 488 (CTB-488) into the anterior 
chamber of one eye of one-month-old mice. On average, $35 \pm 3.56$ (mean \pm s.e.m) SCG neurons projected to the iris in WT mice at P28, less than $0.5 \%$ of the total number of neurons in the ganglion (Figures $2 \mathbf{A}$ and D). These neurons were mostly distributed in the rostral end of the SCG and sent their axons exclusively to the ipsilateral eye, similar to iris innervation in the rat (Luebke and Wright, 1992). In age-matched $\alpha 3 \mathrm{KO}$ mice, the number of SCG neurons projecting to the iris $(37 \pm 1.11$; Figures 2 B and D) was not statistically different from that in WT mice, and most were localized to the rostral end and innervated the iris on the ipsilateral side, as in WT mice. Moreover, in mosaic ganglia, the total number of neurons projecting to the iris was $35 \pm 4.23$ (Figures 2C and D), not statistically

10 different from that in WT or $\alpha 3 \mathrm{KO}$ mice; relevantly, about half of these were $\mathrm{X}^{\mathrm{RFP}}$ neurons (Figure 2E). These data indicate that neither the number nor the projection of SCG neurons to iris depends on whether these neurons receive synaptic activity.

Next, we asked whether synaptic activity of SCG neurons influences target innervation.

15 Therefore, we compared the innervation of irises in WT mice to those in $\alpha 3$ KO mice. Iris muscle in whole mount were immunostained for tyrosine hydroxylase (TH), a marker for sympathetic axons, and the vesicular monoamine transporter 2 (VMAT2), a marker for noradrenergic presynaptic varicosities. The axons from both WT and $\alpha 3$ KO SCG neurons branched extensively to form a network of axons over the iris; however, the density of

20 axons from synaptically-silent $\alpha 3 \mathrm{KO}$ neurons was approximately $50 \%$ less than that of WT mice (Figures $\mathbf{2 F}, \mathbf{G}$ and $\mathbf{H}$ ). These results suggest that the density of axons innervating the iris is influenced either by activity of the target, or activity in the axons, or both.

To determine whether synaptic activity of SCG neurons influences the growth and

25 branching of their axons, we compared the density of axons from $\mathrm{X}^{\alpha 3}$ and $\mathrm{X}^{\mathrm{RFP}}$ neurons. Overall, in mosaic mice, the density of sympathetic axons innervating the iris was not statistically different from that in WT mice, and significantly greater than the iris in $\alpha 3 \mathrm{KO}$ mice (Figures 2F, G and $\mathbf{H}$ ). However, interestingly, the proportion of axons from $\mathrm{X}^{\alpha 3}$ neurons and axons from $\mathrm{X}^{\mathrm{RFP}}$ neurons was approximately equal (Figure 2I). These results

30 indicate that synaptic activity of an SCG neuron does not provide any competitive advantage over synaptically-silent neurons when innervating the same target.

On the other hand, we found no statistical difference, however, in the number of VMAT2 puncta along WT, $\alpha 3 \mathrm{KO}, \mathrm{X}^{\alpha 3}$ and $\mathrm{X}^{\mathrm{RFP}}$ axons innervating the iris when normalized to axon

35 length (Figure 2J). This indicates that differentiation of presynaptic noradrenergic presynaptic varicosities does not require action potential conduction or target activity. 


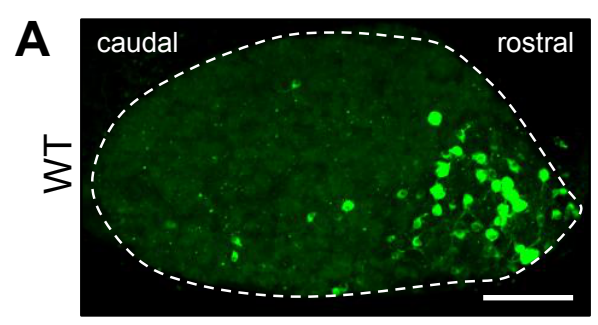

B

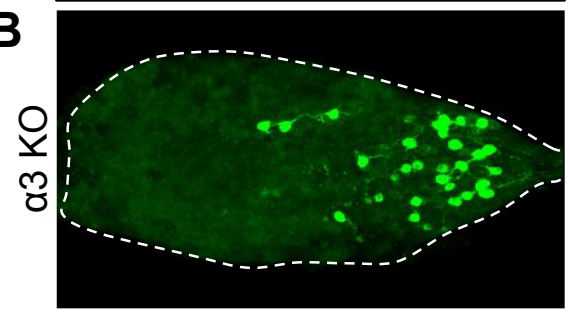

C
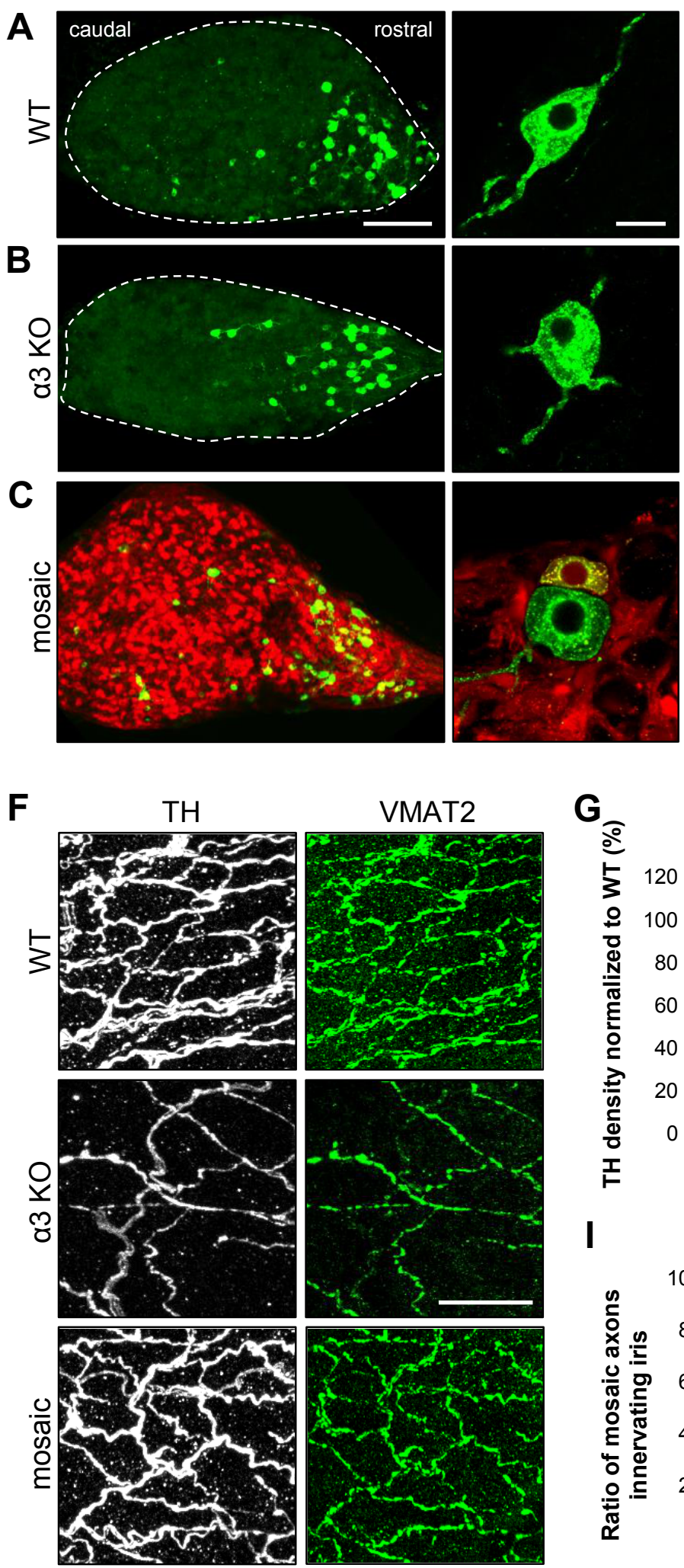

$\mathbf{E}$

D

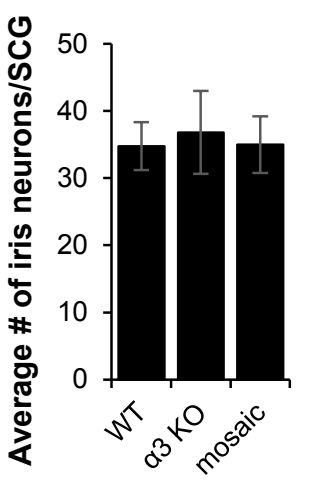

K

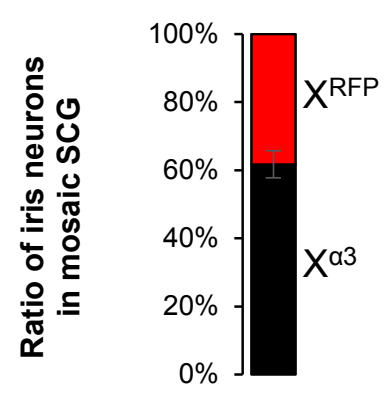

H

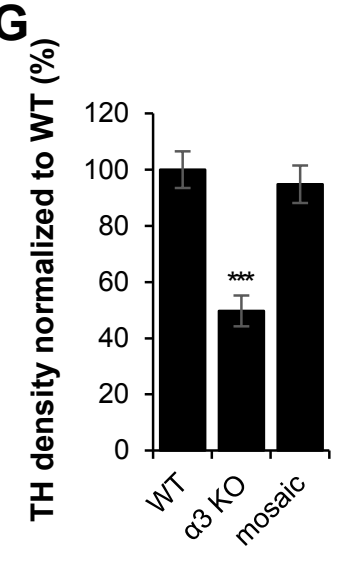

I

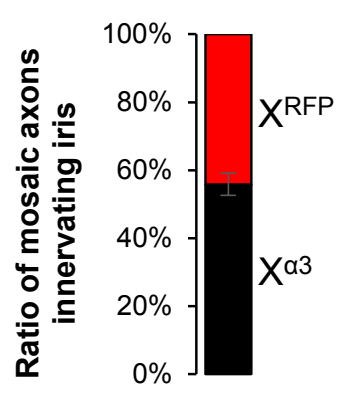

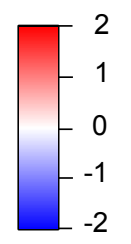

$\log _{2} \mathrm{FC}$
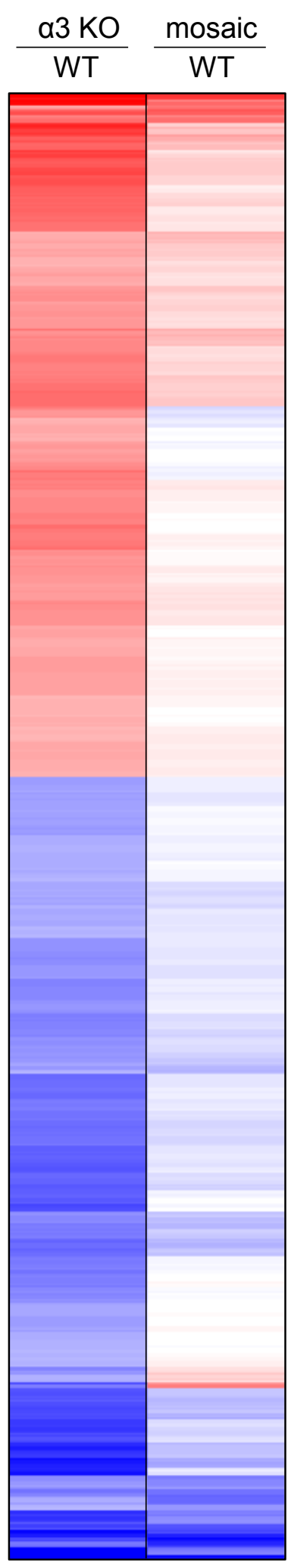
Figure 2. Innervation density of the iris is lower in $\alpha 3 \mathrm{KO}$ mice than in WT mice, yet $\mathrm{X}^{\alpha 3}$ neurons and $\mathrm{X}^{\mathrm{RFP}}$ neurons in mosaic SCG innervate the iris at roughly similar proportions.

(A-C) Left: Maximum intensity projection of CTB-488-labelled neurons (green) in intact

5 SCG. Neurons were retrogradely labelled from the iris in (A) WT, (B) $\alpha 3 \mathrm{KO}$, and (C) mosaic mice at P28. Scale bar, $200 \mu \mathrm{m}$.

Right: CTB-488-labelled neurons (green) at higher magnification.

Scale bar, $20 \mu \mathrm{m}$.

(D) Average number of neurons innervating the iris per WT, $\alpha 3 \mathrm{KO}$ and mosaic SCG at P28.

10 Error bars represent \pm SEM. For WT, $n=8$ SCG (8 mice), for $\alpha 3 \mathrm{KO}, \mathrm{n}=7$ SCG (7 mice), and for mosaic, $n=n=9$ SCG ( 9 mice).

(E) Average ratio of CTB-488-labelled $\mathrm{X}^{\alpha 3}$ neurons (black) and $\mathrm{X}^{\mathrm{RFP}}$ neurons (red) per SCG innervating the iris in mosaic mice at P28, $n=9$ SCG ( 9 mice).

(F) Maximum intensity projections of immunostaining for TH (white; left) and VMAT2

15 (green; right) in iris from WT, $\alpha 3 \mathrm{KO}$, and mosaic mice at P28. Scale bar, $20 \mu \mathrm{m}$.

(G) Average area of the iris innervated by TH-positive axons in WT, $\alpha 3 \mathrm{KO}$ and mosaic mice at P28, normalized to WT.

(H) Average number of VMAT2 puncta per $100 \mu \mathrm{m}^{2}$ square area of iris in WT, $\alpha 3 \mathrm{KO}$ and mosaic mice at P28.

20 (I) Average ratio of TH-positive axons from $\mathrm{X}^{\alpha 3}$ neurons (black) and $\mathrm{X}^{\mathrm{RFP}}$ neurons (red) per iris in mosaic mice at P28.

(J) Average number of VMAT2 puncta per $100 \mu \mathrm{m}$ length of skeletonized TH-positive axons from $\mathrm{WT}, \alpha 3 \mathrm{KO}, \mathrm{X}^{\alpha 3}$ or $\mathrm{X}^{\mathrm{RFP}}$ SCG neurons innervating the iris at P28.

(K) Heatmap generated from bulk RNA sequencing showing a random subset (800 of 6000)

25 of differentially expressed genes $\left(\log _{2} \mathrm{FC}>1.5, \mathrm{p}<0.05\right)$ between WT and $\alpha 3 \mathrm{KO}$ irises (left), and between WT and mosaic irises (right). See also Table S1.

For D, E, G, H, I and J, error bars \pm SEM; ${ }^{* * *} \mathrm{p}<0.001$. For G-J, for WT, $\mathrm{n}=10$ irises (5 mice), for $\alpha 3 \mathrm{KO}, \mathrm{n}=10$ irises ( 5 mice), and for mosaic, $\mathrm{n}=8$ irises ( 4 mice). 


\section{Growth of dendrites on synaptically-silent neurons}

Given that target innervation is known to influence the growth of dendrites on SCG neurons (Miller and Kaplan, 2003; Snider, 1988; Voyvodic, 1989, therefore, next we examined the morphology of sympathetic neurons in mosaic SCG. Our previous work demonstrated that

5 the growth of dendrites was stunted on SCG neurons in $\alpha 3$ KO mice (Chong et al., 2018). Given this, we expected that dendritic growth on $\mathrm{X}^{\mathrm{RFP}}$ neurons would be significantly less than that on $X^{\alpha 3}$ neurons. At P28, synaptically-active $X^{\alpha 3}$ neurons had elaborate dendritic arbors: the average total dendritic outgrowth (TDO) and the number of primary dendrites were not statistically different from P28 SCG neurons in WT mice (Figures 3A, C and D).

10 Surprisingly, synaptically-silent $X^{\mathrm{RFP}}$ neurons in mosaic SCG had dendritic outgrowth that closely matched that of active $\mathrm{X}^{\alpha 3}$ neurons and WT neurons, both in TDO as well as the number of primary dendrites (Figures 3B, C and D).

Most preganglionic axons target their synapses to dendrites (Chong et al., 2018; Forehand,

15 1985). Yet, in the absence of postsynaptic activity, however, more than $50 \%$ of the presynaptic terminals in $\alpha 3 \mathrm{KO}$ mice establish silent synapses on the soma of SCG neurons (Chong et al., 2018). Therefore, we asked whether preganglionic axons target their synapses differently on $X^{\mathrm{RFP}}$ neurons compared to $\mathrm{X}^{\alpha 3}$ neurons. To address this, we labelled P28 neurons in mosaic SCG with DiO and stained for the vesicular acetylcholine transporter

20 (VAChT), a presynaptic marker localized at synapses. Over $90 \%$ of silent synapses on $\mathrm{X}^{\mathrm{RFP}}$ neurons were targeted to dendrites, not statistically different from those on $\mathrm{X}^{\alpha 3}$ neurons or on SCG neurons in WT mice, but in striking contrast to targeting on neurons in $\alpha 3$ KO SCG where over $50 \%$ of contacts are localized on the soma (Figures 3E, F and G) (Chong et al., 2018). 
bioRxiv preprint doi: https://doi.org/10.1101/2020.10.21.349142; this version posted October 22, 2020. The copyright holder for this preprint (which was not certified by peer review) is the author/funder. All rights reserved. No reuse allowed without permission.
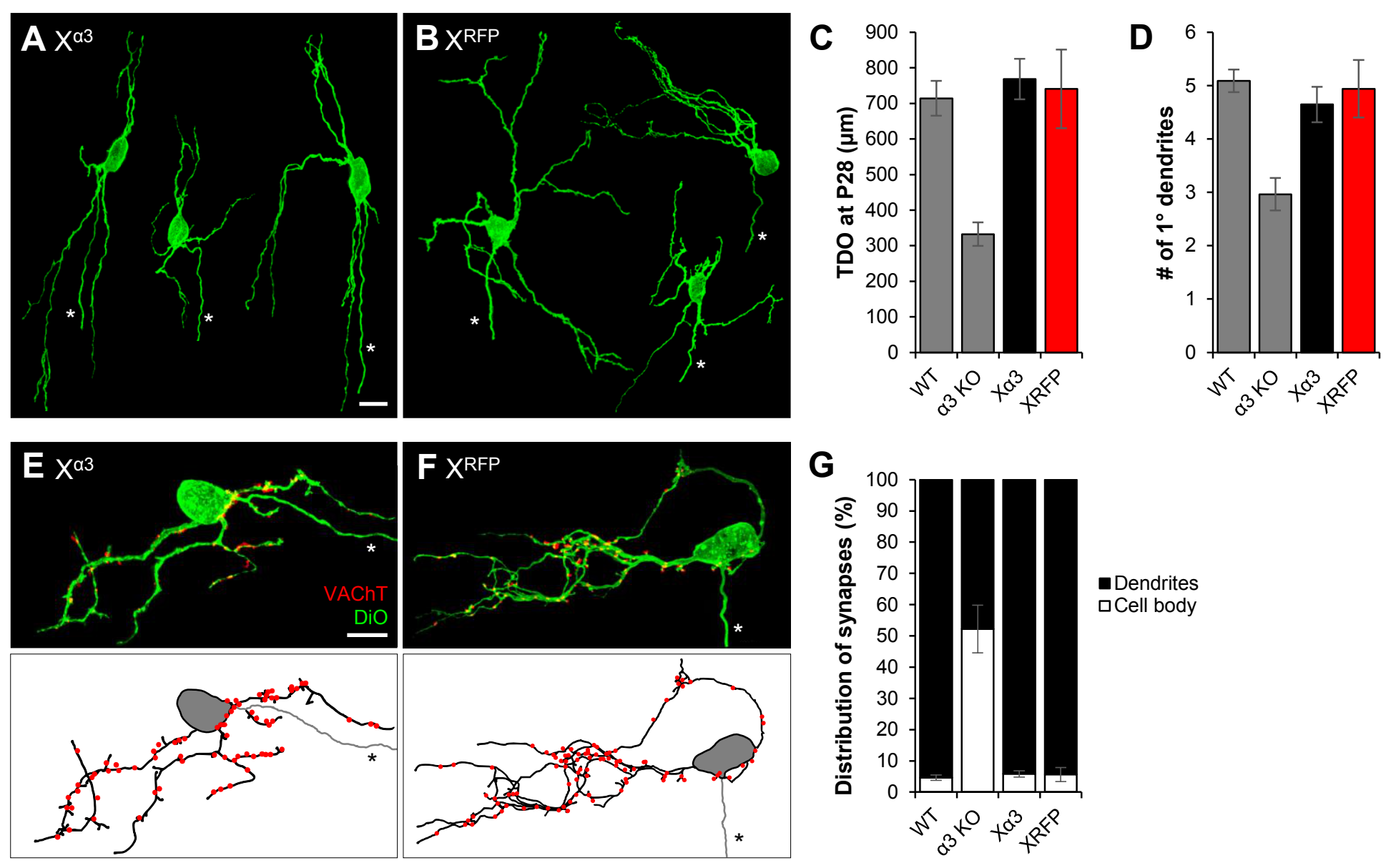
Figure 3. Dendritic growth and synaptic targeting on $X^{\alpha 3}$ and $X^{\mathrm{RFP}}$ neurons.

(A-B) Maximum intensity projections of DiO-labelled (A) $\mathrm{X}^{\alpha 3}$ neurons and (B) $\mathrm{X}^{\mathrm{RFP}}$ neurons from mosaic SCG labelled at P28. All neurons are shown at the same scale; axons are marked by an asterisk. Scale bar, $20 \mu \mathrm{m}$. In each panel, neurons are from different ganglia

5 and have been tiled for comparison. (C-D) Quantification of (C) average total dendritic outgrowth (TD0) per neuron at P28, and (D) average number of primary dendrites per neuron at P28. Black columns represent $\mathrm{X}^{\alpha 3}$ neurons and red columns represent $\mathrm{X}^{\mathrm{RFP}}$ neurons. Grey columns indicate average values from P28 WT and $\alpha 3$ KO neurons for comparison. WT and $\alpha 3 \mathrm{KO}$ data are from Chong et al., 102018.

(E-F) Top: Maximum intensity z-projection of a DiO-labelled (green) (E) $\mathrm{X}^{\alpha 3}$ neuron and (F) $\mathrm{X}^{\mathrm{RFP}}$ neuron in P28 mosaic SCG, immunostained for VAChT (red); axons are marked by an asterisk. VAChT puncta not touching the neuron were removed for clarity. Scale bar, $20 \mu \mathrm{m}$. Bottom: Skeletonized reconstructions showing dendritic arbors (black), axon (grey,

15 marked by an asterisk), and preganglionic axon varicosities (red) determined by VAChT staining.

(G) Average distribution of varicosities on the cell body (open) and dendrites (filled) of $\mathrm{X}^{\alpha 3}$ neurons and $\mathrm{X}^{\mathrm{RFP}}$ neurons in mosaic SCG at P28. WT and $\alpha 3 \mathrm{KO}$ data are from Chong et al., 2018.

20 For $C, D, G$, error bars represent \pm SEM. For $\mathrm{X}^{\alpha 3}, \mathrm{n}=10$ neurons, and for $\mathrm{X}^{\mathrm{RFP}}, \mathrm{n}=10$ neurons (8 mice). 


\section{Activity-dependent gene expression in iris muscle}

Our results strongly suggest that the activity of targets downstream of sympathetic neurons plays an important role in the refinement of preganglionic axons. We tested this possibility by investigating the activity of iris muscle in $\alpha 3 \mathrm{KO}$, WT, and mosaic mice over the first postnatal month in vivo. If activity of the iris in $\alpha 3 \mathrm{KO}$ mice is reduced compared to that in WT and mosaic mice, then presumably this should be reflected in the misexpression of several activity-dependent iris muscle genes. Therefore, as a measure of activity, we quantified the expression of iris genes using bulk RNA sequencing.

10 Of the $\sim 13,000$ genes detected, over $45 \%$ of these genes were dysregulated in iris muscle from $\alpha 3 \mathrm{KO}$ mice compared to those in WT iris muscle: 3520 genes were down-regulated at least 1.5-fold, 2757 genes were up-regulated, and the remaining 7100 were not statistically different (Table S1). On the other hand, fewer than $6 \%$ of the genes in iris muscle from mosaic mice were expressed at significantly different levels from those in WT iris (Figure

15 2K, Table S1), suggesting that the activity of iris muscles in these mosaic mice is normal.

Interestingly, we detected a significant increase in RNA levels for NGF, CNTF and neurturin in iris muscle from $\alpha 3 \mathrm{KO}$ mice but not from mosaic mice; the RNA levels for other sympathetic nerve growth factors were not statistically different among iris muscle from

20 WT, $\alpha 3$ KO, or mosaic mice (Table S1). Nor were there differences in RNA levels for known target-derived factors, such as the BMPs or TGF beta family members (Table S1). Exceptions were: BMP3, BMP receptors $1 \mathrm{a}$ and 2, TGF beta 2, and TGF beta receptor, in which these were 2-3-fold lower in $\alpha 3 \mathrm{KO}$ iris muscle compared to WT. The levels of these five in mosaic iris, however, were not statistically different from WT (Table S1).

Target-derived factors can act at the transcriptional and/or translational level to affect the development of neurons that innervate these targets. Our previous work showed that the phosphorylation of the mRNA translation repressor, 4E-BP is significantly less in SCG neurons in $\alpha 3 \mathrm{KO}$ mice compared to age-matched controls, as are the levels of several

30 proteins (Chong et al., 2018). Moreover, in double 4E-BP/ $\alpha 3 \mathrm{KO}$ mice, the preganglionic axons to SCG neurons in $\alpha 3$ KO mice refine and dendritic outgrowth on SCG neurons are normal, suggesting that enhancing cap-dependent translation can override the effects of synaptic inactivity (Chong et al., 2018). Relevantly, our results indicate that phosphorylated-4E-BP levels in $\mathrm{X}^{\alpha 3}$ and $\mathrm{X}^{\mathrm{RFP}}$ neurons were not statistically different

35 (Figure S1).

\section{Subtypes of SCG neurons}

EPSPs on sympathetic neurons results in a large influx of calcium, either through voltagegated calcium channels or directly through the nicotinic receptors (Belluzzi et al., 1985;

40 Chalazonitis et al., 1980; Rathouz and Berg, 1994; Vernino et al., 1994). In the short-term, 
this increase in intracellular calcium activates several signal transduction pathways and changes the phosphorylation status of transcription factors to alter the expression of a number of genes as neurons mature (Leslie and Nedivi, 2011; Lonze and Ginty, 2002; Yap and Greenberg, 2018). Less is known about the longer-term effects of activity. Therefore, to gain further insight into how the absence of postsynaptic activity over the first postnatal month affects the maturation of developing sympathetic neurons, we measured gene expression in individual SCG neurons. We quantified gene expression profiles using singlecell RNA sequencing (scRNAseq); this approach allowed us to determine neuronal heterogeneity in the SCG at high resolution, and whether different neuronal subtypes were affected equally by the long-term absence of synaptic transmission.

Briefly, to generate single-cell gene expression datasets, we pooled SCG from five to seven P28 mice, dissociated them into a single-cell suspension, loaded $\sim 9,000-10,000$ cells and recovered $\sim 6,000-7,000$ cells (a recovery rate of $\sim 60-70 \%$, consistent with droplet-based

15 technology (Zhang et al., 2019)). The single-cell suspension from dissociated SCG contained both sympathetic neurons and ganglionic non-neuronal cells. We used the R package, Seurat (Butler et al., 2018; Stuart et al., 2019), for all analysis of these single-cell datasets. First, we filtered out cells with fewer than 200 transcripts and genes that were expressed in fewer than 3 cells. Then, we isolated the neuronal population using a set of selection

20 markers for adrenergic neurons: positive for Dbh (dopamine beta hydroxylase, an enzyme involved in noradrenaline synthesis), Ntrk1 (high-affinity receptor for NGF, TrkA), Slc6a2 (noradrenaline transporter), and voltage-gated sodium (Nav) and calcium channel (Cav) genes, and negative for Notch1, 2 or 3, specific markers for the non-neuronal cells.

25 Of the cells that expressed Dbh, Ntrk1, Slc6a2, and were negative for Notch, over 95\% expressed the voltage-gated calcium channel genes, Cacna1a (Cav2.1) or Cacna1b (Cav2.2), genes that code for the $\alpha 1$ subunit of $P / Q$ and N-type calcium channels, respectively. Of the voltage-gated sodium channel genes, approximately 75\% expressed Scn9a (Nav1.7), either alone or together with Scn3a (Nav1.3), while approximately 25\% of the neurons expressed

30 Scn3a alone (Figure S2). Moreover, there were no statistical differences in the expression of voltage-gated sodium and calcium channel genes between these $\alpha 3$ KO sympathetic neurons and those in WT SCG (Figure S2), indicating that the expression of these ion channel genes is not regulated by synaptic transmission.

35 Next, to determine the neuronal heterogeneity in WT SCG, we identified the 1000 most highly variable genes and used a series of algorithms that clustered the neurons into subtypes based on the differential (increased and decreased) expression of these highly variable genes relative to the total population. This process identified 7 sympathetic neuronal subtypes, each subtype comprised of neurons with similar gene expression 40 profiles; we refer to these seven subtypes as $\mathrm{SCG}_{1}-\mathrm{SCG}_{7}$ and visualized them with a uniform 
approximation and projection method (UMAP) (Figure 4A; Figure S3) (Becht et al., 2019). The number of neurons that make up each subtype was not equal, indicating that the specification of neuronal identity does not occur randomly.

5 The marker genes that define each subtype are listed in Table S2. Among these are genes that encode proteins known to be present in subpopulations of sympathetic neurons, including: NPY, galanin, follistatin, endothelin3, 5-HT3 receptor, CHT (high affinity choline transporter), Ret, Ntrk3, Phox2a, phospholipase C $\beta 4$, diacylglycerol kinase, and monoamine oxidase $b$ (Figure 4D). Significantly, there were several marker genes whose

10 expression and function has not been previously documented in sympathetic neurons; these include: the secretin receptor, the relaxin/insulin-like family receptor 1 , olfactory marker protein, hippocalcin, Dickkopf-3, and EPH receptor 5A (Figure 4D). The differential expression of these marker genes suggests that each neuronal subtype signals in a unique manner and likely carries out specific functions.

\section{Activity-dependent gene expression in SCG subtypes}

One issue is whether the effects of postsynaptic activity on gene expression is different in different sympathetic neuronal subtypes. Therefore, we generated single-cell gene expression datasets from $\alpha 3$ KO SCG and used a classifier based on the dataset obtained

20 from WT neurons to sort the $\alpha 3 \mathrm{KO}$ neuronal population into clusters that correspond to those in WT (prediction score, 0.5). Over 95\% of the 1115 neurons from $\alpha 3$ KO SCG clustered into the same 7 neuronal subtypes as the WT neurons (Figure 4B; Figure S3). These data indicate that in the absence of postsynaptic activity, sympathetic neurons continued to mature into the same seven subtypes as WT neurons; however, more $\alpha 3 \mathrm{KO}$

25 neurons than WT neurons were classified as subtypes $\mathrm{SCG}_{2}$ and $\mathrm{SCG}_{6}$, whereas roughly 3fold more WT neurons were classified as $\mathrm{SCG}_{3}$ than $\alpha 3 \mathrm{KO}$ neurons (Figure S3).

Then, after clustering neurons into different subtypes, we determined how each subtype responded to changes in postsynaptic activity. We identified 243 genes that were

30 differentially expressed between WT and $\alpha 3 \mathrm{KO}$ neurons in at least one subtype (Table S3). SCG $_{2}$ had the greatest number of differentially expressed genes (160 genes), whereas $\mathrm{SCG}_{7}$ had the lowest number (20 genes). 

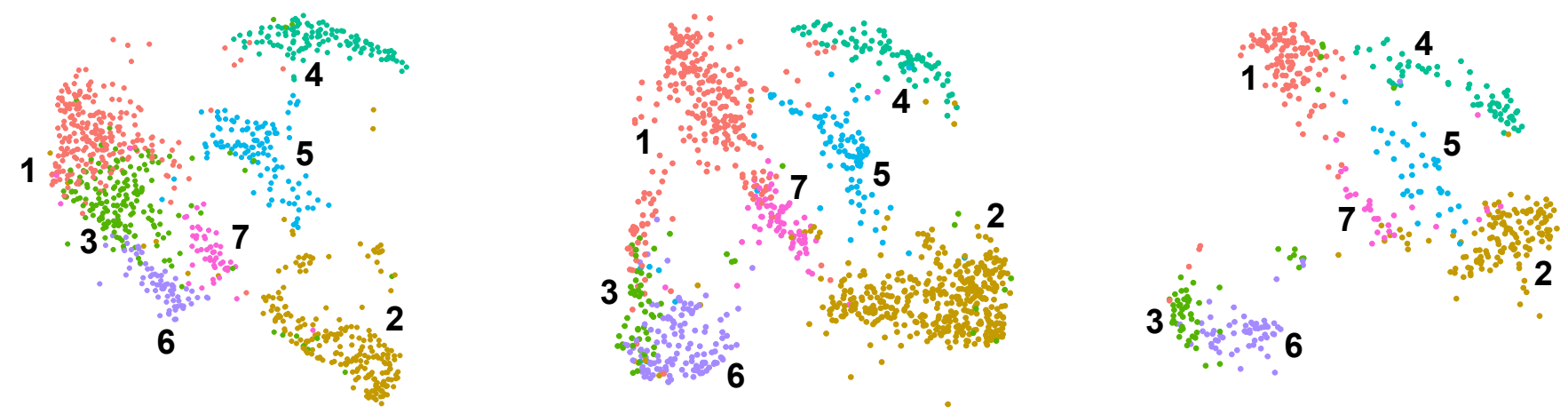

\begin{tabular}{|c|c|c|c|c|c|c|c|}
\hline & SCG1 & SCG2 & SCG3 & SCG4 & SCG5 & SCG6 & SCG7 \\
\hline Neuropeptide Y (Npy) & 1.126 & -2.745 & 0.173 & -0.565 & 0.299 & -0.319 & -1.469 \\
\hline Galanin (Gal) & 1.009 & -1.397 & 0.222 & -0.176 & 0.102 & -1.450 & -1.546 \\
\hline Follistatin (Fst) & 0.869 & -1.310 & 0.224 & -0.278 & 0.252 & -0.777 & -1.210 \\
\hline Endothelin 3 (Edn3) & -1.028 & 1.315 & -0.789 & 0.268 & -0.436 & -0.880 & -0.538 \\
\hline Serotonin receptor 3B (Htr3b) & -0.835 & 0.226 & -0.023 & 0.753 & -0.284 & 0.116 & -0.184 \\
\hline High-affinity choline transporter (SIc5a7) & -0.280 & -0.173 & -0.172 & -0.055 & 0.144 & 0.984 & -0.203 \\
\hline Ret proto-oncogene (Ret) & -0.571 & 0.514 & -0.532 & 0.771 & -0.306 & -0.167 & -0.484 \\
\hline Neurotrophic receptor tyrosine kinase 3 (Ntrk3) & -0.415 & -0.668 & -0.112 & 0.025 & 0.136 & 1.317 & 0.169 \\
\hline Paired like homeobox 2A (Phox2a) & 0.413 & -0.371 & 0.260 & -0.450 & -0.067 & -0.346 & 0.001 \\
\hline Phospholipase C ß4 (PIcb4) & 0.712 & -1.050 & 0.154 & -0.219 & 0.194 & -0.531 & -0.316 \\
\hline Diacylglycerol kinase (Dgkh) & 0.761 & -0.582 & -0.106 & -0.123 & 0.028 & -0.776 & -0.371 \\
\hline Monoamine oxidase B (Maob) & 0.408 & -0.779 & 0.162 & -0.559 & 0.251 & 0.068 & 0.300 \\
\hline Secretin receptor (Sctr) & 1.040 & -0.841 & -0.234 & -0.232 & 0.001 & -0.771 & -0.735 \\
\hline Relaxin/insulin-like recptor 1 (Rxfp1) & 0.617 & -1.062 & 0.350 & -0.092 & 0.193 & -0.725 & -0.813 \\
\hline Olfactory marker protein (Omp) & -0.191 & 0.723 & -0.243 & -0.226 & -0.273 & -0.839 & 0.060 \\
\hline Hippocalcin (Hpca) & -0.201 & -0.200 & -0.086 & -0.036 & 0.150 & 0.697 & 0.106 \\
\hline kopf WNT signaling pathway inhibitor 3 (Dkk3) & 0.236 & -0.335 & 0.087 & 0.282 & -0.013 & -0.749 & -0.037 \\
\hline Eph receptor A5 (Epha5) & 0.551 & -0.846 & 0.187 & 0.008 & 0.097 & -0.497 & -0.301 \\
\hline
\end{tabular}

E
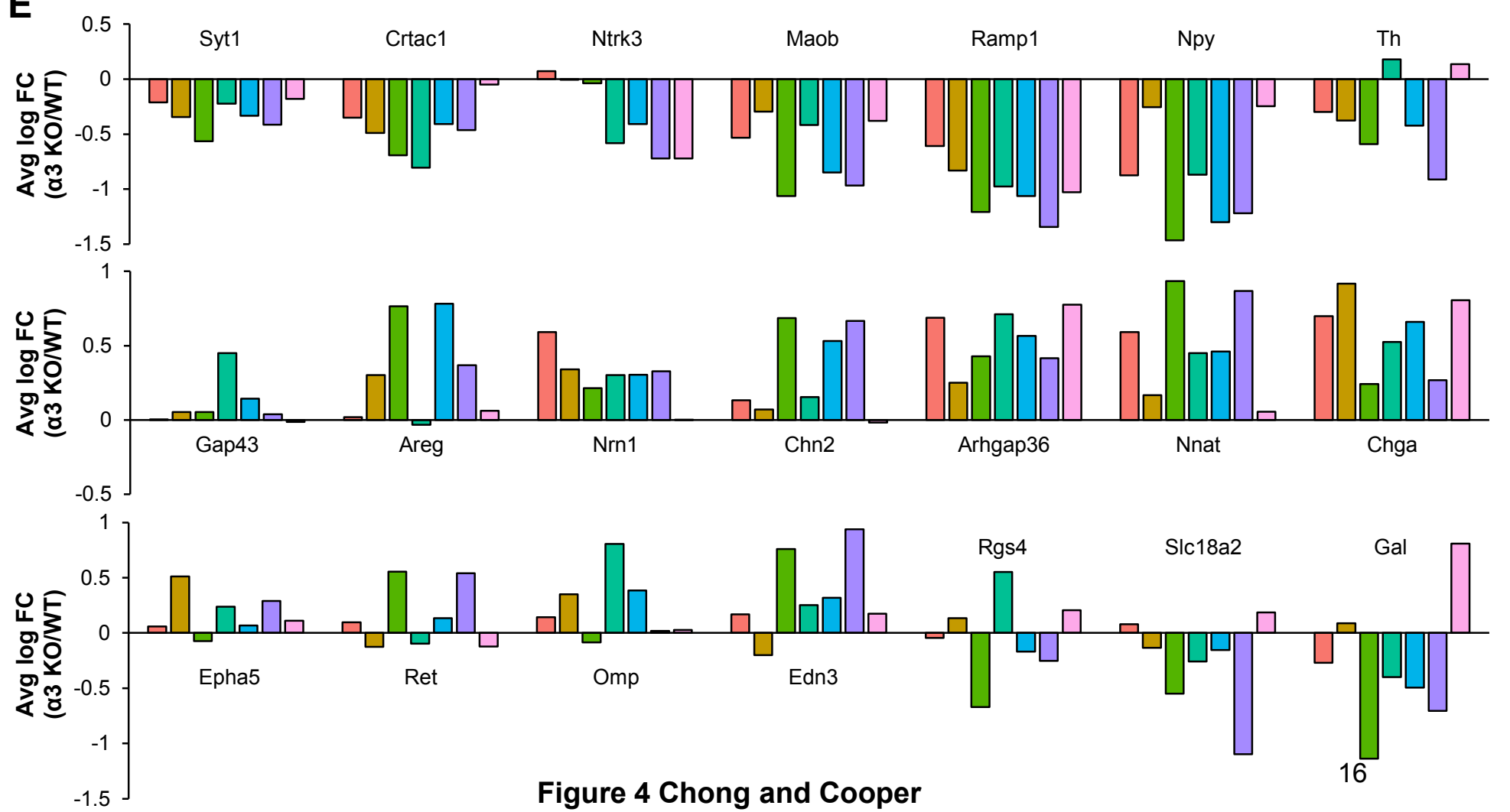


\section{Figure 4. WT and $\alpha 3$ KO SCG neurons cluster into 7 subtypes.}

(A-C) UMAPs show clustering of neurons from (A) WT, (B) $\alpha 3 \mathrm{KO}$ and (C) mosaic SCG into 7 subtypes. See also Figures S2, S3 and S4, and Tables S4 and S5.

(D) Heat map showing the average $\ln (x+1)$ fold change of selected marker genes between neurons of a particular SCG subtype compared to the average expression in all other subtypes. Each row was scaled independently. See also Table S2.

(E) Subtypes of SCG neurons respond differently to changes in postsynaptic activity. Graphs show $\ln (\mathrm{x}+1)$ fold change $(\alpha 3 \mathrm{KO} / \mathrm{WT})$ in each subtype for selected genes that were differentially expressed between WT and $\alpha 3$ KO SCG neurons. Negative fold change

10 indicates downregulation in $\alpha 3 \mathrm{KO}$ neurons. The color of each bar refers to the SCG subtype shown in A. See also Table S3. 
In the absence of synaptic activity, many genes were either up-regulated or down regulated in all subgroups, including some genes known to be involved in refinement of presynaptic inputs or dendritic growth on CNS neurons (Leslie and Nedivi, 2011; Riccomagno and Kolodkin, 2015). Interestingly, several genes, including those for neuropeptides, signaling molecules, and growth factor receptors were either up-regulated or down-regulated in some subtypes but unchanged in others (Figure 4E). These data indicate that activitydependent regulation of many genes depends on subtype.

A particularly striking example is the expression of two markers for cholinergic neurons:

10 CHT, the high-affinity choline transporter, and VAChT, the vesicular acetylcholine transporter. $\mathrm{SCG}_{3}$ neurons responded to the absence of synaptic transmission by increasing the expression of CHT 40-fold (Figures 5A, B and G) and VAChT by 90-fold (Figures 5D, E and I). We also observed a significant increase in these cholinergic markers in $\mathrm{SCG}_{6}$ neurons. These data indicate that synaptic transmission in developing sympathetic neurons acts to repress a cholinergic phenotype.

Relevantly, synaptic activity in the SCG had little influence on the genes expressed by nonneuronal cells. We identified 2400 non-neuronal cells that clustered into 8 different subtypes (Figure S4); the marker genes for each cluster suggested that clusters 1, 2 and 4

20 appear to be ganglionic satellite cells, cluster 2 appears to be cells that make up the surrounding capsule, and cluster 6 appears to be mainly immune cells (Table S4). In comparing non-neuronal cells from WT SCG to those from $\alpha 3$ KO SCG, we identified only 22 genes that were differentially expressed by at least 1.25-fold (Table S5). The majority of these were housekeeping genes, and the expression of only 2 genes were different by more

25 than 1.75-fold. These results indicate that synaptic activity in the SCG has little influence of the genes expressed by non-neuronal cells. None of these 22 genes have been implicated in the differentiation of developing sympathetic neurons.

\section{Effects of the target on activity-dependent gene expression in SCG neurons}

30 Synaptically-silent SCG neurons in $\alpha 3 \mathrm{KO}$ mice develop differently from synaptically-silent $\mathrm{X}^{\mathrm{RFP}}$ neurons in mosaic SCG with respect to dendritic growth and refinement of converging preganglionic inputs. Consequently, we asked whether the absence of synaptic transmission on $\mathrm{X}^{\mathrm{RFP}}$ neurons in mosaic SCG induced a similar change in gene expression.

35 To address this, we generated single-cell gene expression datasets from mosaic SCG and used the same algorithms to cluster neurons using the classifier based on the WT data set. We recovered 1708 neurons from mosaic SCG and over 95\% of these neurons clustered into the seven subtypes. As confirmed by our imaging experiments, half the neurons expressed RFP due to random X-inactivation; approximately two-thirds of these had detectable levels of RFP mRNA and were represented in all seven subtypes. 
bioRxiv preprint doi: https://doi.org/10.1101/2020.10.21.349142; this version posted October 22, 2020. The copyright holder for this preprint (which was not certified by peer review) is the author/funder. All rights reserved. No reuse allowed without permission.

\section{A WT CHT}

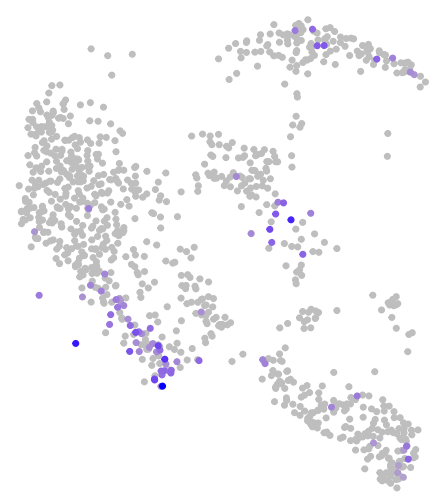

D WT VAChT

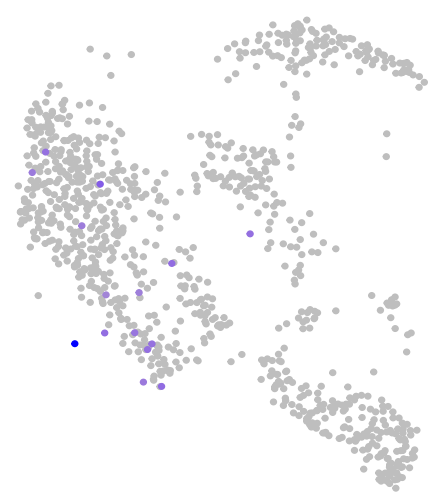

\section{B a3 KO CHT}

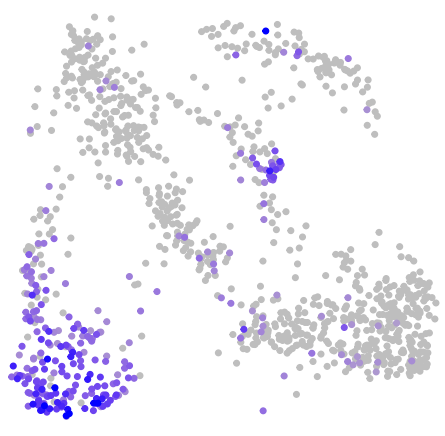

E $\alpha 3$ KO VAChT

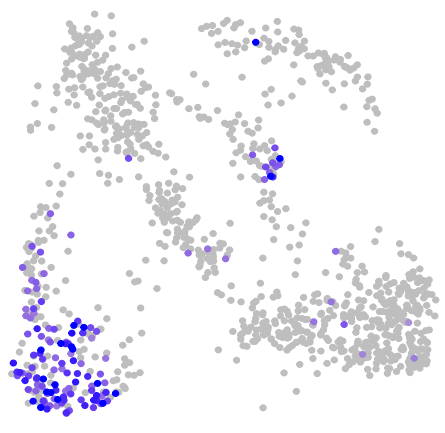

C X ${ }^{\text {RFP }} \mathrm{CHT}$

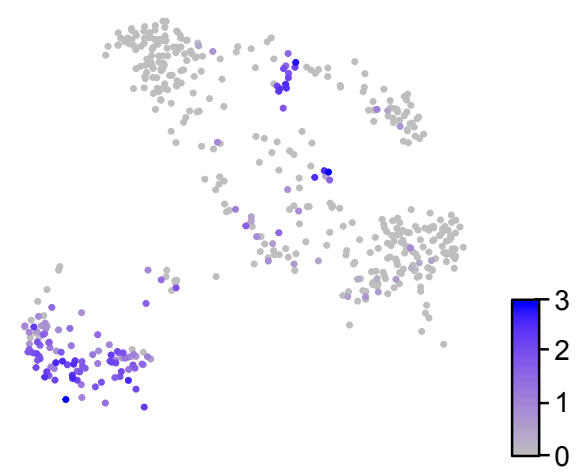

F X RFP VAChT

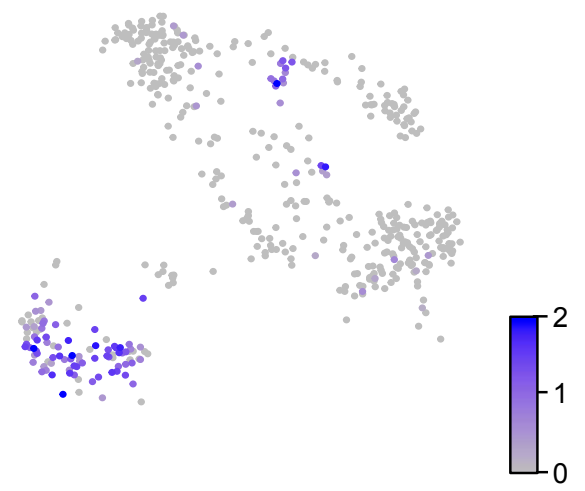

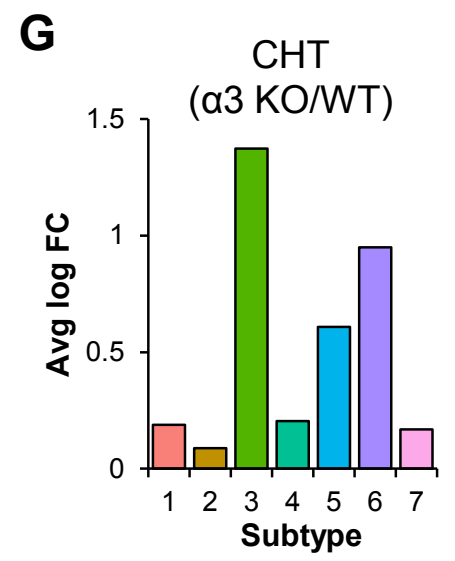
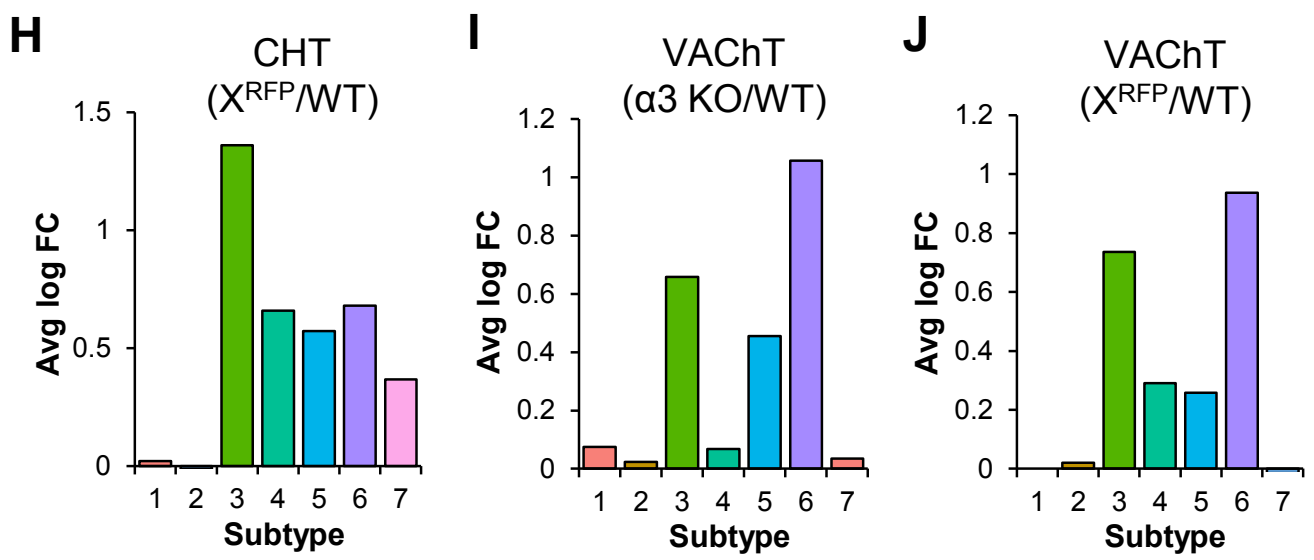

Figure 5 Chong and Cooper 
Figure 5. Cholinergic markers are expressed at higher levels in $\alpha 3$ KO and XFP SCG neurons than in WT SCG neurons.

(A-C) UMAPs indicating expression level of CHT1 (Slc5a7) per neuron and their distribution between subtypes in (A) WT neurons, (B) $\alpha 3$ KO neurons, and (C) $\mathrm{X}^{\mathrm{RFP}}$ neurons.

(D-F) UMAPs indicating expression level of VAChT (Slc18a3) per neuron and their distribution between subtypes in (D) WT neurons, (E) $\alpha 3$ KO neurons, and (F) $\mathrm{X}^{\mathrm{RFP}}$ neurons.

(G, H) Graphs show $\ln (\mathrm{x}+1)$ fold change in each subtype for CHT1 (Slc5a7) between

10 corresponding clusters in (G) WT and $\alpha 3 \mathrm{KO}$ neurons and (H) WT and XFP neurons. (J, K) Graphs show $\ln (\mathrm{x}+1)$ fold change in each subtype for VAChT (Slc18a3) between corresponding clusters in (J) WT and $\alpha 3$ KO neurons and (K) WT and $\mathrm{X}^{\mathrm{RFP}}$ neurons. 
Like $\alpha 3$ KO neurons, there was a significant increase in the number of $\mathrm{X}^{\mathrm{RFP}} \mathrm{SCG}_{3}$ and $\mathrm{SCG}_{6}$ neurons that had increased levels of mRNA for both CHT (Figures 5C and $\mathbf{H}$ ) and VAChT (Figures 5F and J) compared to $\mathrm{WT} \mathrm{SCG}_{3}$ and $\mathrm{SCG}_{6}$ neurons (Figure 4C; Figure S3). On the other hand, the expression of CHT and VAChT mRNA in $\mathrm{X}^{\alpha 3}$ neurons was not significantly different from that in neurons from WT SCG. These data reinforce the idea that synaptic transmission in developing sympathetic neurons acts to repress a cholinergic phenotype.

Of the 243 differentially expressed genes in $\alpha 3$ KO SCG, 156 genes were expressed in $\mathrm{X}^{\mathrm{RFP}}$ neurons at levels comparable to those in neurons $\alpha 3$ KO SCG, including CHT and VAChT

10 (Table S3). These data indicate that these 156 genes are directly regulated by synaptic activity.

On the other hand, over 35\% (87 of 243) of these genes were expressed in $\mathrm{X}^{\mathrm{RFP}}$ neurons at levels comparable to those in neurons in WT SCG (Table S3), indicating that these 87 genes

15 are regulated by processes other than ones directly initiated by excitatory synaptic transmission and elevations in intracellular calcium; some of these 87 genes, alone or working in concert, may play important roles in the processes that govern dendritic growth and refinement of converging preganglionic inputs on sympathetic neurons during postnatal development.

\section{Discussion:}

Our results show that $\mathrm{X}^{\mathrm{RFP}}$ neurons and a3 KO neurons develop differently, even though both are synaptically silent. This difference indicates that the impact of synaptic activity on the growth and innervation of developing neurons is dependent on their context. Most

25 notably, converging inputs to $\mathrm{X}^{\mathrm{RFP}}$ neurons refined, similar to those innervating $\mathrm{X}^{\alpha 3}$ neurons and WT SCG neurons, whereas those innervating $\alpha 3$ KO SCG neurons do not. That preganglionic inputs to $\mathrm{X}^{\mathrm{RFP}}$ neurons refine in the absence of postsynaptic activity contradicts widely-held views about refinement or pruning of inputs (Chong et al., 2018; Cohen-Cory, 2002; Kano and Hashimoto, 2009; Katz and Shatz, 1996; Lichtman and

30 Colman, 2000; Zhang and Poo, 2001). Our results indicate that some mechanism(s) other than postsynaptic depolarization initiates the refinement of preganglionic axons. For clues, we focused on features that are different between synaptically-silent $\mathrm{X}^{\mathrm{RFP}}$ neurons in mosaic SCG and synaptically-silent sympathetic neurons in $\alpha 3$ KO SCG.

35 It seems unlikely that genetic manipulations to create these two mouse strains account for the differences. Both strains have a deletion in $\alpha 3$ on chromosome 9; however, mosaic mice have an additional modification in the $\mathrm{X}$ chromosome to express $\alpha 3$ cDNA or RFP. As a result of X-chromosome inactivation, in female mosaic mice, 50\% of the neurons in the SCG express RFP and do not have functional nAChRs, similar to those in $\alpha 3$ KO SCG. 
Consequently, preganglionic inputs fail to evoke postsynaptic depolarizations on both $\alpha 3$ KO SCG neurons and $\mathrm{X}^{\mathrm{RFP}}$ neurons. $\mathrm{X}^{\alpha 3}$ neurons, on the other hand, generate preganglionic nerve-evoked EPSPs that are similar to those on age-matched sympathetic neurons in WT SCG. As an aside, we observed that the level of $\alpha 3$ mRNA in $\mathrm{X}^{\alpha 3}$ neurons is only $\sim 10 \%$ of WT (Figure S1); this indicates that developing WT sympathetic neurons express $\alpha 3 \mathrm{mRNA}$ at levels several fold greater than that needed for functional synapses. Moreover, nAChRs on sympathetic neurons are pentamers containing $\alpha 3-\beta 4$ dimers (the fifth subunit is likely $\beta 2$ ) (Anand et al., 1991; Cooper et al., 1991). In WT mice, $\beta 4, \alpha 3$, and $\alpha 5$ nAChR subunit genes are clustered on chromosome 9, and the $\alpha 3$ gene has an enhancer that is situated in the 3' end of the $\beta 4$ gene (McDonough and Deneris, 1997), an arrangement that likely facilitates the synthesis of $\alpha 3-\beta 4$ dimers. This gene cluster, however, is disrupted in mosaic mice, yet $\mathrm{X}^{\alpha 3}$ neurons are still able to assemble and target functional nAChRs to synapses.

A number of reports indicate that astrocytes and microglia have a role in refining neural connections (Chung et al., 2013; Neniskyte and Gross, 2017; Riccomagno and Kolodkin, 2015; Wilton et al., 2019). However, it seems doubtful that this occurs in sympathetic ganglia: unlike astrocytes in the CNS, ganglionic satellite cells have a one-to-one relationship with sympathetic neurons, which make it improbable that satellite cell signaling at active synapses on $\mathrm{X}^{\alpha 3}$ neurons could affect preganglionic connections on

20 distant $\mathrm{X}^{\mathrm{RFP}}$ neurons. More compelling, we found no significant difference between geneexpression profiles in satellite cells from WT SCG and those from $\alpha 3$ KO SCG (Figure S4). Given this, instructing signal(s) for refinement of preganglionic inputs presumably come from elsewhere.

25 Conceivably, a local activity-dependent factor emanating from $\mathrm{X}^{\alpha 3}$ neurons causes indiscriminate elimination of inputs to $\mathrm{X}^{\mathrm{RFP}}$ neurons. But this seems unlikely, however, because elimination of preganglionic inputs is not a random process, but one that is usually thought to improve functional circuitry. The pupillary reflex is a good example. For pupillary reflexes to function independently, for instance while attending to a visual scene,

30 SCG neurons innervating the iris require a unique set of preganglionic inputs to ensure that the nervous system can exert specific control over iris muscle without affecting other parts of sympathetic system (Neuhuber and Schrödl, 2011). Iris-specific neurons make up only $\sim 0.5 \%$ of the total number of neurons in the SCG, and for the reflex to function properly, a specific set of preganglionic axons need to innervate a specific set of SCG neurons.

35 Therefore, it is likely that the targets initiate the signals instructing preganglionic inputs to refine.

Target-derived signals, such as NGF and BDNF, acting in a retrograde manner, play critical roles in the development and innervation of neurons (Choo et al., 2017; Cohen-Cory et al., 2010; Davies, 2009; Deppmann et al., 2008; Harrington and Ginty, 2013; Huang and 
Reichardt, 2001; Purves et al., 1988; da Silva and Wang, 2011; Singh et al., 2008; Snider and Lichtman, 1996; Zweifel et al., 2005). Moreover, although often not stated explicitly, the release of these target-derived retrograde factors is activity-dependent. In $\alpha 3 \mathrm{KO}$ mice, however, the activity of targets of sympathetic nerves is reduced considerably or absent, whereas in mosaic SCG, on the other hand, the neighboring $\mathrm{X}^{\alpha 3}$ neurons, driven by preganglionic nerves, activate targets that they share with $\mathrm{X}^{\mathrm{RFP}}$ neurons. Accordingly, $\mathrm{X}^{\mathrm{RFP}}$ neurons receive activity-dependent, retrograde signals from their targets, whereas $\alpha 3 \mathrm{KO}$ sympathetic neurons do not.

10 From these results, we offer a new model for refinement in sympathetic ganglia. Our model suggests that activity-dependent retrograde signaling from distal synapses at the target specifies which preganglionic inputs should persist in innervating postganglionic neurons. Thus, rather than local signals at synapses on postsynaptic neurons, our model highlights the importance of overall circuit activity and retrograde signals to initiate the refinement of

15 inputs 2-3 synapses upstream. A recent study on parasympathetic neurons concluded similarly that in motor systems, target innervation dictates the connections of central synapses (Sheu et al., 2017).

Support for this idea comes from our investigation of iris muscle. We found that over $45 \%$

20 of the 13,000 genes detected in iris muscle $(5928 / 13,026)$ were dysregulated in iris from $\alpha 3 \mathrm{KO}$ mice, whereas less than $6 \%$ were dysregulated in iris from mosaics. These experiments were intended to quantify the effects of muscle inactivity, and not as a screening method, but the results serve to suggest that one or more proteins encoded by these $\sim 6,000$ genes, acting alone or in concert, may be involved in specifying which

25 preganglionic axons should maintain their innervation of iris-specific SCG neurons.

Relatedly, the density of sympathetic axons innervating iris muscle in $\alpha 3 \mathrm{KO}$ mice was $50 \%$ less than that in either WT or mosaic mice. It is not that the axons of synaptically-silent neurons grow less well since in mosaic mice, the axonal density of synaptically-silent $\mathrm{X}^{\mathrm{RFP}}$

30 neurons innervating the iris was similar to that of synaptically-active $\mathrm{X}^{\alpha 3}$ neurons. Instead, these results suggest that the activity of the target plays a major role in determining the target's innervation density.

Relevantly, the density of target innervation has been shown to be regulated by retrograde 35 growth factors (Davies, 2009; Huang and Reichardt, 2001). Messenger RNA levels for most of these growth factors in iris muscle from $\alpha 3 \mathrm{KO}$ mice were not statistically different than those in WT iris. Interestingly, we detected a significant elevation in neurturin, NGF, and CNTF mRNA in iris muscle from $\alpha 3 \mathrm{KO}$ mice, suggesting that the expression of these genes is regulated by muscle activity. Surprisingly, however, the up-regulation of these growth

40 factor genes negatively correlated with the growth of sympathetic axons, suggesting that 
these growth factors by themselves are not sufficient to increase the growth of axons at the target. Presumably other factors, possibly specific to each target, are required to work in conjunction with these growth factors. For example, it was recently shown that S100b specifically promotes sympathetic innervation of brown adipose tissue (Zeng et al., 2019).

Previous work showed a significant decrease in dendritic outgrowth on $\alpha 3$ KO sympathetic neurons (Chong et al., 2018), consistent with a role for activity in promoting the growth of dendrites on sympathetic neurons (Miller and Kaplan, 2003; Snider, 1988; Voyvodic, 1989). In contrast, dendritic outgrowth on $X^{\mathrm{RFP}}$ neurons was not statistically different from

10 those on $\mathrm{X}^{\alpha 3}$ neurons in mosaic SCG or from age-matched WT SCG neurons. That synaptically-silent neurons extend normal dendrites is not unique to $\mathrm{X}^{\mathrm{RFP}}$ SCG neurons. Similar results on dendritic growth were observed on a sparse population of CA1 neurons with deletions in all their ionotropic glutamate receptors: the dendritic trees on these synaptically-silent neurons were not statistically different from those on neighboring 15 control neurons (Lu et al., 2013). While the refinement of converging inputs to these CA1 neurons was not measured, the density of synapses on the dendrites was not statistically different from control.

Several studies have demonstrated that target-derived retrograde signals, transported to 20 soma, alter gene expression at the transcriptional and translational level (Harrington and Ginty, 2013; Kaplan and Miller, 2000; Laplante and Sabatini, 2012; Lipton and Sahin, 2014; Segal and Greenberg, 1996; Tasdemir-Yilmaz and Segal, 2016). Previous work showed that $\alpha 3$ KO SCG neurons have decreased amounts of phosphorylated 4E-BP, a repressor of capdependent mRNA translation, and have a corresponding change in the level of several

25 proteins (Chong et al., 2018). Poor target innervation by $\alpha 3 \mathrm{KO}$ neurons may account for these changes. We find no statistical difference in phosphorylated-4E-BP among $\mathrm{X}^{\mathrm{RFP}}$ and $\mathrm{X}^{\alpha 3}$ neurons in mosaic SCG, or SCG neurons in WT mice. Therefore, the signaling events that phosphorylate 4E-BP in $\mathrm{X}^{\mathrm{RFP}}$ neurons does not result from preganglionic nerve-evoked depolarization; more likely, they come from activity-dependent retrograde signaling from

30 the target. Interestingly, enhancing mRNA translation by removing 4E-BP genetically from $\alpha 3 \mathrm{KO}$ mice led to the refinement of preganglionic axons and the growth of dendrites by SCG neurons (Chong et al., 2018). We propose that low-levels of target-derived factors in $\alpha 3 \mathrm{KO}$ mice are not sufficient to maintain dendritic growth on sympathetic neurons or initiate refinement of preganglionic axons, whereas, enhancing cap-dependent translation

35 by removing 4E-BP lowers the threshold for the action of these target-derived factors.

In WT SCG, the majority of neurons are adrenergic; however, a small minority that innervate sweat glands and the periosteum are cholinergic (Ernsberger and Rohrer, 1999; Schotzinger and Landis, 1990). We found a large up-regulation, both in the number of 40 neurons and in average expression, in cholinergic marker genes, CHT and VAChT in $\alpha 3$ KO 
SCG, and a concomitant decrease in adrenergic marker gene VMAT2. Moreover, we found a similar up-regulation of cholinergic marker genes in $\mathrm{X}^{\mathrm{RFP}}$ neurons but not in $\mathrm{X}^{\alpha 3}$ neurons in mosaic SCG. Together, these results indicate that preganglionic nerve-evoked depolarization and related calcium influx at the soma-dendritic domain plays a critical role in maintaining an adrenergic phenotype in sympathetic neurons. Research on neonatal rodent SCG neurons developing in cell culture showed that molecules released from the targets of sympathetic nerves caused the neurons to switch their transmitters from norepinephrine to acetylcholine (Furshpan et al., 1979; Yamamori et al., 1989), and consistent with our in vivo results, electrical stimulation and membrane depolarization

10 could prevent the induction of cholinergic differentiation (Walicke et al., 1977). Embryonically, sympathetic neuroblasts display a mixed noradrenergic and cholinergic phenotype, and transcriptional regulatory mechanisms and neurotrophic tyrosine kinase receptors working, through cross-regulatory interactions, determine whether a sympathetic precursor develops into an adrenergic or cholinergic neuroblast (Furlan et al.,

15 2013). It is not clear whether synaptic activity engages this mechanism to prevent SCG neurons from acquiring cholinergic properties. Our results, however, are in line with those from other systems showing that synaptic activity influences the expression of neurotransmitters (Spitzer, 2012).

20 Using scRNAseq to analyze basal gene expression profiles, we show that SCG are composed of several subtypes of sympathetic neurons, similar to that of other sympathetic ganglia (Furlan et al., 2016). Interestingly, we found that the expression of several marker genes in SCG neurons has not been described previously and may underlie unsuspected functional aspects of these neurons. Equally relevant, we show, unexpectedly, that different subtypes

25 respond differently to endogenous synaptic activity. For example, the up-regulation of cholinergic genes does not occur in all $\alpha 3 \mathrm{KO}$ sympathetic neuronal subtypes, and is particularly pronounced in $\mathrm{SCG}_{3}$ and $\mathrm{SCG}_{6}$, subtypes that represent $\sim 20 \%$ of the total neuronal population. This also indicates that with respect to cholinergic differentiation, some subtypes are more affected by the absence of synaptic transmission than others.

We found over 240 genes were differentially regulated in subtypes of $\alpha 3$ KO SCG compared to WT control neurons. This is consistent with reports that excitatory synaptic activity regulates the expression of immediate early genes that subsequently alter the expression of downstream target genes and influence neuronal development and innervation (Leslie and

35 Nedivi, 2011; Yap and Greenberg, 2018). On the other hand, comparing gene expression in $\alpha 3$ KO SCG to that in $\mathrm{X}^{\mathrm{RFP}}$ neurons, we found more than 35\% (87 genes) that were dysregulated in $\alpha 3 \mathrm{KO}$ neurons were expressed at near WT levels in at least one subtype of $\mathrm{X}^{\mathrm{RFP}}$ neurons. Since preganglionic inputs do not evoke postsynaptic depolarizations on either $\alpha 3 \mathrm{KO}$ or $\mathrm{X}^{\mathrm{RFP}}$ neurons, this indicates that the regulation of these $\sim 87$ genes is not mediated by synaptic EPSPs and related calcium influx. Rather, these genes must be 
regulated by other factors; the most likely are activity-dependent signals emanating from the targets.

In summary, our results from mosaic SCG demonstrate that presynaptic inputs refine in the absence of postsynaptic activity. In addition, we show a large diversity in neuronal subtypes in SCG and that these different subtypes respond to the absence of synaptic activity during postnatal development depends on context, including the targets they innervate, and in particular, if they share targets with synaptically-active neurons.

\section{Materials and Methods:}

$10 \quad$ Mice

To generate $\mathrm{X}^{\alpha 3} \mathrm{X}^{\mathrm{RFP}}$ mosaic mice, $\alpha 3$ rat cDNA was ligated into a previously modified Gateway entry vector pENTR1a (Thermo Fisher Scientific, Waltham, MA) between the human ubiquitin $\mathrm{C}$ promoter (UbiC) and bovine growth hormone polyA site (Yurchenko et al., 2007). The pENTR1a entry vector was then recombined in vitro into the HPRT gateway destination vector (Thermo Fisher Scientific), which contained homology arms for the HPRT locus on the X chromosome (Figure S1). The recombined vector was electroporated into BK4 embryonic stem (ES) cells, which have a partial deletion in the HPRT gene. Successful homologous recombination inserted the UbiC- $\alpha 3$ construct and restored HPRT expression, which conferred resistance to $0.1 \mathrm{mM}$ hypoxanthine, $0.0004 \mathrm{mM}$ aminopterin, $0.016 \mathrm{mM}$ thymidine (HAT). HAT-resistant ES cells were injected into blastocysts that were transplanted into recipient females. Chimeric progeny that had germline expression of UbiC- $\alpha 3$ from the $\mathrm{X}$ chromosome were crossed with $\alpha 3 \mathrm{KO}$ mice and with $\mathrm{X}^{\mathrm{RFP}}$ mice (Yurchenko et al., 2007) to generate $\alpha 3 \mathrm{KO} ; \mathrm{X}^{\alpha 3} \mathrm{X}^{\mathrm{RFP}}$ mice. All genotyping was performed by PCR:

25 Common UbiC FWD: 5' - GCA GTG CAC CCG TAC CTT TGG GAG - 3’

X ${ }^{\alpha 3}$ REV: 5' - CTT AAA GAT GGC CGG CGG GAT CC - 3'

X RFP REV: 5' - CGT AGG CCT TGG AGC CGT ACT GG - 3'

Mice with a deletion in the $\alpha 3 \mathrm{nAChR}$ subunit gene ( $\alpha 3 \mathrm{KO}$ ) were maintained on an outcrossed background because inbred C57BL/6J $\alpha 3 \mathrm{KO}$ mice die during the first week after birth (Krishnaswamy and Cooper, 2009). Briefly, inbred C57BL/6J $\alpha 3+/-$ mice were mated to CD-1 WT mice and F1 $\alpha 3+/-$ heterozygotes were used as breeders to produce $\alpha 3$ KO mice and WT littermates on a mixed C57BL/6J x CD-1 background. All genotyping was performed by PCR:

35 Common FWD: 5' - GTT ATG CAC GGG AAG CCA GGC TGG - 3'

WT REV: 5' - GAC TGT GAT GAC GAT GGA CAA GGT GAC - 3' $\alpha 3$ KO REV: 5' - TGG CGC GAA GGG ACC ACC AAA GAA CGG - 3’ 
All procedures for animal handling were carried out according to the guidelines of the Canadian Council on Animal Care.

\section{Electrophysiological Recordings}

5 SCG were acutely dissected in oxygenated Tyrode's solution (pH 7.4) supplemented with glucose $(5.6 \mathrm{mM})$ and choline $(0.01 \mathrm{mM})$, pinned down securely with minutia pins on a Sylgard-coated petri dish, mounted to the stage of an upright confocal microscope (BX$61 \mathrm{~W}$, Olympus), and viewed through a $40 \mathrm{X}$ water-immersion objective (N.A. 0.8, Olympus). To record intracellularly from ganglion cells, $80-120 \mathrm{~m} \Omega$ glass microelectrodes (G150F-4;

10 Warner Instruments, Hamden, CT) were made with a DMZ universal puller (Zeitz Instruments, Munich, Germany). Stable intracellular recordings were achieved with a high inertial precision microdrive (Inchworm 8200; EXFO, Quebec, Canada) attached to a micromanipulator (MPC-200/ROE-200; Sutter Instruments, Novato, CA) that drove the electrode through the ganglion at $4 \mu \mathrm{m}$ steps. The recording electrode was filled with $1 \mathrm{M}$

15 KAc. To confirm the identity of neurons in mosaic SCG of $\mathrm{X}^{\alpha 3} \mathrm{X}^{\mathrm{RFP}}$ mice, $10 \mathrm{mM}$ Alexa Fluor 488 hydrazide (Thermo Fisher Scientific) in 200mM KCl was added to the electrode solution and neurons were imaged with confocal microscopy (Olympus). The recording electrode was connected with a silver chlorided wire to the head stage of an Axoclamp 2A amplifier (Axon Instruments, Union City, CA) used in current-clamp mode to deliver

20 depolarizing or hyperpolarizing current pulses through the recording electrode. Ionic currents were filtered at $3 \mathrm{kHz}$ (low-pass cutoff) and $1 \mathrm{~Hz}$ (high-pass cutoff) and digitized at $50 \mathrm{kHz}$. Stimulation and data acquisition were performed with N-Clamp (Neuromatic, UK).

To measure the convergence of preganglionic axons innervating a sympathetic neuron, the

25 preganglionic nerve was stimulated with increasing strength while holding the neuron at approximately $-90 \mathrm{mV}$ to prevent EPSPs from triggering action potentials. In some experiments, the sodium channel blocker QX314 was also included in the recording electrode to prevent action potentials.

30 Analysis: All data analysis of electrophysiological recordings was performed offline using Igor Pro (WaveMetrics, Lake Oswego, OR). Increasing the strength of the stimulus to the preganglionic nerve activated axons of different threshold, which resulted in discrete jumps in the amplitude of the EPSPs. To isolate the average EPSP evoked by an axon and all axons of lower threshold, at least 10 traces were averaged for each discrete jump. The

35 number of discrete jumps was used as an estimate of the number of axons innervating the neuron.

\section{Adenoviruses}

Full-length $\alpha 3$ neuronal nAChR subunit cDNA was ligated into pAdTrack-synapsin 1 (Ad$\alpha 3 /$ Syn), and replication-deficient viral vectors were generated (He et al., 1998) and titered 
in duplicate with Adeno-X Rapid Titer Kit, (Clontech Lab, Mountain View, CA) (Krishnaswamy and Cooper, 2009). Mice were infected with Ad- $\alpha 3 /$ Syn adenovirus at a concentration of $\sim 10^{7} \mathrm{pfu} / \mathrm{mL}$ diluted in sterile $1 \mathrm{X}$ PBS. For P5-P6 mice, $\sim 50 \mu \mathrm{L}$ was injected into the intraperitoneal cavity, and for P23-P26 mice, $\sim 200 \mu \mathrm{L}$ was injected intravenously into the tail vein. Injections were performed using a 29G x 1/2" $1 \mathrm{~mL}$ insulin syringe (Bencton Dickinson, Franklin Lakes, NJ).

\section{Imaging}

Images were acquired on an upright confocal microscope (BX-61W, Olympus) with a 60X,

10 N.A. 1.42 PlanApo N oil-immersion objective (Olympus) at a scan speed of $8 \mu \mathrm{s} / \mathrm{pixel}$ and an image depth of 12 bits. Laser lines were activated sequentially to avoid bleed-through of signals. All image analysis was performed with FIJI/ImageJ (NIH, Bethesda, MD).

\section{Lipophilic tracer labelling for dendrite morphology}

15 Lipophilic tracer 3,3'-Dioctadecyloxacarbocyanine perchlorate (DiO) (Thermo Fisher Scientific) was used to sparsely label a random subset of preganglionic axons and postsynaptic neurons in the SCG. Briefly, freshly dissected ganglia with intact pre- and postganglionic nerves were fixed in 1\% PFA (pH 7.4) in 0.1M PB for 2 hours at room temperature, rinsed with 1X PBS and embedded in 3\% agarose Type I-B (Sigma-Aldrich, St.

20 Louis, MO) dissolved in 1X PBS. A scalpel blade was used to slice through the pre- and postganglionic nerves to expose a cross-sectional area of the nerve. Platinum wires were used to gently apply fine crystals of DiO to the postganglionic nerve to label sympathetic neurons and their dendritic structures. After labelling, ganglia were kept in the dark in $1 \mathrm{X}$ PBS for 5-6 days to allow for tracers to diffuse along lipid membranes. Excess DiO was

25 removed and ganglia were sliced into $100 \mu \mathrm{m}$ sections with the Compresstome VF-200 (Precisionary Instruments Inc., Greenville, NC) using a solid zirconia ceramic injector blade (Cadence Inc., Staunton, VA). Sections were either mounted with Vectashield (Vector Laboratories, Burlingame, CA) and immediately imaged, or first processed with immunohistochemistry before mounting and imaging.

Analysis: Only neurons with complete dendritic arbours and an identifiable axon were analyzed. For neurons with a dendritic arbour that extended beyond one field of view, neighboring z-stacks were acquired and stitched together with XuvTools (Emmenlauer et al., 2009). To quantify the length and number of dendritic branches, neurons were

35 reconstructed in 3-D and the Simple Neurite Tracer plugin (Longair et al., 2011) was used to trace dendrites. Primary dendrites were categorized as those directly leaving the cell body.

For representative images, neurons were tiled and DiO-labelled neurites of other neurons were removed from the field of view for clarity. On each plane of the z-stack, all DiO- 
labelled neurites that were not connected to the dendritic arbour of the neuron of interest, as determined by 3-D reconstruction and dendritic tracing, were removed for clarity. After removing non-connected neurites, the z-stack was used to produce a maximum intensity zprojection of the neuron. For illustration purposes, figures show the maximum intensity zprojections.

Synaptic targeting on DiO labelled neurons SCG were fixed and the postganglionic nerve was labelled with DiO and incubated in the dark for 5-6 days as described above. Labelled SCG were sliced into $100 \mu \mathrm{m}$ sections and

10 incubated in blocking solution for 2 hours at room temperature [Blocking solution: 10\% normal donkey serum (Millipore, Billerica, MA) and 0.3\% Tween 20 (Fisher Scientific, Waltham, MA) in $1 \mathrm{X}$ PBS], in the primary antibody for 48 hours at $4^{\circ} \mathrm{C}$ [Primary antibody: Rabbit anti-VAChT (1:3000; Synaptic Systems)], and in the secondary antibody diluted in 10\% normal donkey serum for 2 hours at room temperature [Secondary antibody: Alexa

15 Fluor 647 goat anti-rabbit (1:500; Thermo Fisher Scientific)].

Analysis: To examine synaptic targeting, VAChT puncta located on a neuron of interest were identified on each plane of a z stack. To be counted as a synapse, VAChT puncta were: (i) colocalized with the DiO membrane label; (ii) at least $0.5 \mu \mathrm{m}$ in diameter; and (iii)

20 spanned at least two optical slices (optical thickness was $0.45 \mu \mathrm{m} /$ slice). Synapses were categorized as being on the cell body or on the dendritic arbour. The density of synapses on the cell body was calculated by dividing the number of synapses on the cell body by the total surface area of the cell body. To estimate the surface area of the cell body, the circumference of the cell body on each plane was multiplied by the thickness of the optical

25 slice and summed. To calculate the density of synapses on dendrites, the number of synapses on dendrites was divided by the total dendritic outgrowth (TDO). TDO was measured using 3-D reconstructed neurons and the Simple Neurite Tracer plugin as described above. For representative images, VAChT puncta that were not located on the neuron of interest were removed for clarity. To illustrate clearly the location of VAChT

30 puncta, maximum intensity z-projections of DiO-labelled SCG neurons were thresholded and skeletonized, and the locations of VAChT puncta were indicated with red circles.

\section{Phosphorylated-4E-BP (P-4E-BP) immunohistochemistry}

SCG were dissected and immediately fixed in $2 \%$ PFA (pH 7.4) in 0.1M PB with 5mM EGTA

35 (to chelate $\mathrm{Ca}^{2+}$ ions released from intracellular stores by fixation) for 1 hour at room temperature. After fixation, ganglia were sliced into $100 \mu \mathrm{m}$ sections and incubated in blocking solution for 1 hour at room temperature [Blocking solution: 10\% normal donkey serum, 0.3\% Tween 20, and 0.05\% Triton X-100 (Fisher Scientific) in 1X PBS], in primary antibodies for 48 hours at $4^{\circ} \mathrm{C}$ [Rabbit anti-P-4E-BP (1:600; Cell Signaling Technology, 40 Danvers, MA), goat anti-MAP-1A (1:360; Santa Cruz Biotechnology, Dallas, TX)], and in 
secondary antibodies diluted in 10\% normal donkey serum for 1 hour at room temperature [Secondary antibodies: TRITC donkey anti-rabbit (1:500; Jackson ImmunoResearch Laboratories), Alexa Fluor 647 donkey anti-goat (1:500; Thermo Fisher Scientific)]. Analysis: All image acquisition parameters (HV, gain, offset, laser power) were kept constant between samples. Z stacks of 20 images were used to generate a summed zprojection and regions of interest (ROI), each consisting of one neuronal cell body, excluding the nucleus, were selected from the MAP-1A channel. Average fluorescence intensity for each ROI was measured from the MAP-1A channel, and ROI were transferred to the P-4E-BP1 channel to measure the corresponding fluorescence intensity. Figures show maximum intensity z-projections.

Sympathetic innervation of the iris

Irises were dissected from albino mice and fixed with 2\% PFA (pH 6.0) in $0.1 \mathrm{M}$ PB for 10 minutes at room temperature. To achieve a consistent state of contraction between

15 samples, carbachol was added to the fixative for a final concentration of $500 \mu \mathrm{M}$. During fixation, irises were left attached to the cornea to maintain the structure and carefully separated from the cornea with a scalpel blade after fixation. Irises were incubated in blocking solution for 1 hour at room temperature [Blocking solution: 10\% normal donkey serum, $0.3 \%$ Tween 20, and $0.1 \%$ Triton X-100 in $1 \mathrm{X}$ PBS], in primary antibodies for 24

20 hours at $4^{\circ} \mathrm{C}$ [Primary antibodies: Mouse anti-tyrosine hydroxylase (TH) clone LNC1 (1:500; Millipore) and rabbit anti-vesicular monoamine transporter 2 (1:1000; Phoenix Pharmaceuticals, Burlingame, CA)], and in secondary antibodies diluted in 10\% normal donkey serum for 1 hour at room temperature [Secondary antibodies: Alexa Fluor 405 goat anti-rabbit (1:500; Thermo Fisher Scientific) and Alexa Fluor 647 goat anti-mouse IgG1

25 (1:500; Thermo Fisher Scientific)].

Analysis: All image acquisition parameters (HV, gain, offset, laser power) were kept constant between samples. Images were taken at the radial muscles halfway between the inner (pupil) and outer (attachment to sclera) edge of the iris. Z-stacks were split into

30 separate channels for TH and VMAT2, and the same threshold values for each channel were applied to all samples. On each channel, the mean fluorescence intensity of the pixels above threshold were recorded. Innervation density was expressed in two ways: (1) TH-positive area over a given area, and (2) number of VMAT2 puncta in a given area. To calculate the TH innervation density, a maximum intensity z-projection was generated from the TH

35 channel, thresholded, and the TH area was divided by the total area. To calculate the VMAT2 innervation density, a maximum intensity z-projection was generated from the VMAT2 channel, single pixel noise was removed with the "Despeckle" filter and the "Find maxima" filter was used to automatically count puncta (noise=700), and the number of puncta was then divided by the total area. To calculate the number of VMAT2 puncta along 40 TH-positive fibers, a maximum intensity z-projection of the TH channel was thresholded, 
skeletonized, and total fiber length was measured. Figures show a maximum intensity zprojection for each channel.

To determine the ratio between $\mathrm{X}^{\alpha 3}$ axons and $\mathrm{X}^{\mathrm{RFP}}$ axons in mosaic mice, subsets of 3 slices were summed through a maximum intensity z-projection and individual axon fibers were identified on the TH channel. The lengths and areas of the axons were measured, and the number of VMAT2 puncta along the axon was counted. Each axon was then overlaid onto the RFP channel, and categorized as either RFP-positive, RFP-negative, or undetermined.

\section{$\underline{\text { Retrograde labelling with cholera toxin subunit B (CTB) }}$}

10 P28 mice were anaesthetized with isoflorane and the cornea was punctured with a 29G hypodermic needle (Bencton Dickinson) to allow for outflow of aqueous humour. Using the same puncture site, $\sim 2 \mu \mathrm{L}$ of cholera toxin subunit B conjugated to Alexa Fluor 488 (CTB488; Thermo Fisher Scientific) was injected into the anterior chamber of the eye using a 33G x 1/2" TSK SteriJect hypodermic needle (Air-Tite Products, Virginia Beach, VA) fitted

15 onto a $25 \mu \mathrm{L}$ Gastight Hamilton syringe (Hamilton Company, Reno, NV). SCG were dissected after $\sim 4$ days, fixed in 1\% PFA in $0.1 \mathrm{M}$ PB for 1 hour at room temperature and sliced into $100 \mu \mathrm{m}$ sections for imaging.

Analysis: All labelled neurons were intensely fluorescent and easily identified: mean

20 intensity fluorescence (excluding the nucleus) was at least 10X greater than background fluorescence intensity. For mosaic SCG, labelled neurons were superimposed on the RFP channel and categorized as RFP-positive or RFP-negative. Low magnification figures for illustration purposes were obtained using a 10X air objective (N.A. 0.3, Olympus).

\section{$25 \quad$ Gene expression in the iris}

Six irises were collected from 3 mice for each genotype (WT, $\alpha 3 \mathrm{KO}$ and mosaic mice). Irises were dissected in DNase/RNase-free 1X PBS (DNase/RNase-free 10X PBS from Thermo Fisher Scientific diluted in DNase/RNase-free $\mathrm{H}_{2} \mathrm{O}$ ) and immediately flash frozen in liquid nitrogen. Total RNA was extracted in parallel using the RNeasy Mini Kit (Qiagen,

30 Hilden, Germany). Frozen tissue was homogenized (Polytron PT 2100, Kinematica, Luzern, Switzerland) in buffer RLT with $\beta$-mercaptoethanol. Homogenates were processed according to the RNeasy Mini Kit protocol and included a DNase I (Qiagen) treatment step to avoid contamination from genomic DNA. RNA quantity and purity was assessed with a NanoDrop2000c (NanoDrop, Wilmington, DE; 260/230 and 260/280 values > 2.0) and

35 RNA integrity was assessed with a Bioanalyzer (Agilent Technologies, Santa Clara, CA; RIN > 8.0). cDNA libraries were sequenced with an Illumina NovaSeq 6000 System (S4, PE100; Illumina) at $25 \mathrm{M}$ reads.

Analysis: Count data for each transcript were generated from paired-end FASTQ files with 
Ensembl v96 transcriptome and transcripts were summarized into genes and imported into R Studio (R Core Team, 2013; RStudio Team, 2015) with the tximport package (Soneson et al., 2016). Genes with low counts were filtered out (cpm >=3), and differential analysis was performed with the EdgeR package (McCarthy et al., 2012; Robinson et al., 2010) in R using generalized linear models (GLMs) for non-normal distributions. Genes with a $\log _{2}$ fold change $>0.58496(1.5 \mathrm{X})$ at a $\mathrm{p}$ value $<0.05$ were considered as differentially expressed.

\section{Ultrastructural studies}

10 Mosaic SCG were dissected, fixed in 4\% PFA (pH 7.4) in 0.1M PB for 1 hour at room temperature, sliced into $100 \mu \mathrm{m}$ sections and fixed for an additional 10 minutes at room temperature. Sections were rinsed with $0.1 \mathrm{M} \mathrm{PB}$, imaged with a $40 \mathrm{X}$ water-immersion objective (N.A. 0.8, Olympus) on an upright confocal microscope (Olympus). After imaging, sections were fixed again in 2\% PFA/2\% glutaraldehyde for 30 minutes at room

15 temperature. After fixation, SCG were rinsed with $0.1 \mathrm{M}$ PB for 30 minutes and incubated in $1 \%$ osmium tetroxide/1.5\% potassium ferricyanide in $\mathrm{H}_{2} \mathrm{O}$ for 1 hour at room temperature. Ganglia were rinsed briefly with $\mathrm{H}_{2} \mathrm{O}$ to remove osmium tetroxide and dehydrated in a graded series of ethanol concentrations from 30-100\%, where each interval lasted 10 minutes, with the $100 \%$ ethanol step repeated 3 times. After dehydration, ganglia were

20 incubated in $100 \%$ propylene oxide for 15 minutes twice and incubated in a propylene oxide:EMbed812 mixture at a ratio of 1:1, 1:2, 1:3 and pure EMbed812 for 1 hour each, and polymerized in EMbed 812 at $60^{\circ} \mathrm{C}$ for 24 hours. Thin sections of ganglia were cut on an ultramicrotome, stained with $2 \%$ aqueous uranyl acetate and $3 \%$ lead citrate, and viewed with a Tecnai Spirit $120 \mathrm{kV}$ transmission electron microscope with Gatan Ultrascan $40004 \mathrm{k}$

$25 \quad \mathrm{x} 4 \mathrm{k}$ CCD Camera System Model 895.

\section{$\underline{\alpha 3}$ mRNA expression from $X$ chromosome}

RNA extraction and quantitative PCR (qPCR) were optimized, validated and performed in accordance with the MIQE guidelines (Bustin et al., 2009; Taylor et al., 2010). SCG from P28

30 WT, $\alpha 3+/-$ heterozygote, and mosaic mice were dissected and immediately flash frozen in liquid nitrogen. Total RNA was extracted using the RNeasy Mini Kit (Qiagen). Frozen tissue was homogenized (Polytron PT 2100, Kinematica) in buffer RLT with $\beta$-mercaptoethanol. Homogenates were processed according to the RNeasy Mini Kit protocol and included a DNase I (Qiagen) treatment step to avoid contamination from genomic DNA. RNA quantity

35 and purity were assessed with a NanoDrop2000c (NanoDrop) and RNA integrity was assessed by running 400ng on a gel. 260/230 and 260/280 values were consistently $>2.0$, and $28 \mathrm{~S}$ and $18 \mathrm{~S}$ rRNA bands were consistently clear and sharp, with the 28S band approximately twice as intense as the $18 \mathrm{~S}$ band. Reverse transcription (iScript Reverse Transcription Supermix for RT-qPCR, Bio-Rad, Hercules, CA) was performed immediately after RNA extraction and used 200ng of RNA per reaction volume of $20 \mu \mathrm{L}$. No reverse 
transcriptase controls were included for each reaction to test for contamination from genomic DNA. cDNA was stored at $-20^{\circ} \mathrm{C}$.

qPCR reactions were performed using SsoFast EvaGreen Supermix with Low ROX (Bio-Rad, Hercules, CA) on the Eco Real-Time PCR System (Illumina, San Diego, CA). Cycling parameters were as follows: UDG incubation $2 \mathrm{mins}$ at $50^{\circ} \mathrm{C}$; Polymerase activation $30 \mathrm{~s}$ at $95^{\circ} \mathrm{C}$; PCR cycling $\left(5 \mathrm{~s}\right.$ at $95^{\circ} \mathrm{C}, 15 \mathrm{~s}$ at $\left.60^{\circ} \mathrm{C}\right)$ for 40 cycles. All primers were $90-100 \%$ efficient at an annealing temperature of $60^{\circ} \mathrm{C}$. Samples were run in duplicates and controls without reverse transcriptase and template consistently showed no amplification.

10 In $\alpha 3 \mathrm{KO}$ mice and in mosaic mice, the endogenous $\alpha 3 \mathrm{nAChR}$ subunit gene on chromosome 9 had a deletion in exon 5 that prevented the formation of functional $\alpha 3$ subunit protein. The forward primer was designed to bind within exon 4 and reverse primer to bind within the deleted region in exon 5 , and therefore would not recognize any potential mRNA generated from the $\mathrm{KO}$ allele. In addition, intron-spanning primer pairs reduced

15 amplification of residual genomic DNA. Standard curves were generated from an 8-point 4X serial dilution of cDNA to determine primer efficiencies. $\alpha 3$ mRNA levels were normalized to GAPDH expression.

$\alpha 3$ FWD: 5' - GTG GAG TTC ATG CGA GTC CCT G - 3' (in exon 4) $\alpha 3$ REV: 5' - TAA AGA TGG CCG GAG GGA TCC - 3' (in exon 5)

GAPDH FWD: 5' - CTG GCA TGG CCT TCC GTG TT - 3'

GAPDH REV: 5' - TAC TTG GCA GGT TTC TCC AGG CG - 3’

\section{Single cell RNA sequencing (scRNAseq) of sympathetic ganglia}

25 Single cell RNA libraries were generated using 10X Genomics droplet-based technology at the Genome Québec Innovation Centre (Montréal, Canada). SCG from five to seven P28 mice were pooled for each genotype (WT, $\alpha 3 \mathrm{KO}$ and mosaic mice). Freshly dissected SCG were incubated on a shaker in $1 \mathrm{mg} / \mathrm{mL}$ collagenase (Sigma-Aldrich) and $5 \mathrm{mg} / \mathrm{mL}$ bovine serum albumin (BSA; Sigma-Aldrich) in $1 \mathrm{X}$ HBSS (pH 7.4) for 30 minutes at $37^{\circ} \mathrm{C}$, followed

30 by $1 \mathrm{mg} / \mathrm{mL}$ trypsin (Worthington Biochemical Corporation, Lakewood, NJ) in 1X HBSS (pH 7.4) for 1 hour at $37^{\circ} \mathrm{C}$. To dissociate ganglia into a single cell suspension, SCG were gently titurated with a fire-polished pipette, washed with 10\% horse serum and 1X HBSS, and filtered through a $30 \mu \mathrm{m}$ cell strainer (Miltenyi Biotec, Bergisch Gladbach, Germany). Cells were reconstituted in calcium- and magnesium-free 1 X PBS containing $400 \mu \mathrm{g} / \mathrm{mL}$ non-

35 acetylated BSA at concentration of $\sim 1000$ cells $/ \mu \mathrm{L}$ in $2 \mathrm{~mL}$ LoBind Eppendorf tubes (Thermo Fisher Scientific). Cell viability was determined with a $0.4 \%$ trypan blue solution (Thermo Fisher Scientific) and was consistently $>90 \%$. Cell suspensions were kept on ice and loaded onto the 10X Loading Single Cell Chip within 30 minutes to 1 hour after preparation. For all samples, $\sim 9,000-10,000$ cells were loaded and $\sim 6,000-7,000$ cells were recovered for a recovery rate of $\sim 60-70 \%$, consistent with this technology (Zhang et 
al., 2019). RNA molecules were captured, tagged with a cellular barcode and a unique molecular identifier barcode, and reversed transcribed to generate cDNA libraries for sequencing.

5 Analysis: cDNA libraries were amplified and multiplexed for sequencing with the Illumina HiSeq 4000 (Illumina) to generate read data. Read data were grouped based on barcodes and aligned using Cell Ranger software to a custom reference package consisting of the mouse genome version GRCm38/mm10 with the addition of rat $\alpha 3$ and mRFP1 cDNA.

10 Count matrices were analyzed using the Seurat package v3.0 (Butler et al., 2018; Stuart et al., 2019) in Rstudio. Cells that had fewer than 200 transcripts, and genes that were expressed in fewer than 3 cells were filtered out. To be considered a neuron, cells expressed Dbh, Ntrk1, Slc6a2, either Scn3a or Scn9a (or both), and either Cacna1a or Cacna1b (or both), and not Notch1, 2 or 3. To isolate the non-neuronal population, we

15 selected cells that expressed Notch1, 2 or 3 but not Dbh, Slc6a2, Scn3a, Scn9a, Cacna1a, Cacna1b nor Npy. The fraction of mitochondrial counts per cell was consistently $<0.2$ and there were no outliers with high transcript counts that may represent doublets. The neuronal subset was normalized to the count depth per cell and transformed via a natural log-plus-one transformation $(\ln (x+1))$. For clustering analysis, data were scaled to have

20 zero mean and variance of 1 . Scaled expression equally weighed high- and low-expressing genes for clustering analysis. The top 2000 highly variable genes were identified and used for preprocessing with principal components analysis (PCA). The WT dataset was clustered and used as a classifier to sort $\alpha 3$ KO neurons, $\mathrm{X}^{\alpha 3}$ neurons and $\mathrm{X}^{\mathrm{RFP}}$ neurons into the same clusters identified in the WT population (prediction score $>0.5$ ). Clusters were visualized

25 using a uniform approximation and projection method (UMAP) (Becht et al., 2019). To test for differential expression, a Wilcoxon rank sum test was used. Genes were considered to be differentially expressed if their average $\ln (x+1)$ fold change was \pm 0.25 , with a Bonferroni adjusted p-value $<0.05$.

30 Of the differentially expressed genes between $\alpha 3$ KO SCG and WT SCG, we determined whether their levels in $\mathrm{X}^{\mathrm{RFP}}$ neurons from mosaic SCG were comparable to levels in $\alpha 3 \mathrm{KO}$ SCG, suggesting they are directly regulated by postsynaptic activity, or whether they were comparable to those in WT SCG, suggesting that these genes are indirectly regulated by activity. Using the normalized average expression level, the difference was calculated for

35 each differentially expressed gene between $\alpha 3$ KO SCG and WT SCG. Then, 25\% of the difference was either added onto the $\alpha 3 \mathrm{KO}$ value if it was down-regulated compared to WT, or subtracted from the $\alpha 3 \mathrm{KO}$ value if it was up-regulated compared to WT. If the $\mathrm{X}^{\mathrm{RFP}}$ average expression level surpassed this $25 \%$ threshold in the direction of the WT value, the gene was considered to be restored towards WT values. 


\section{Statistical analysis}

The number of samples (n) and p-values are reported in the figures and corresponding figure legends. In all figures, error bars represent \pm s.e.m., ${ }^{*} \mathrm{p}<0.05,{ }^{* * *} \mathrm{p}<0.001$. To test for statistical differences between two samples, unpaired two-tailed t tests assuming equal variance were used.

Acknowledgments: We are grateful to Drs. A. Krishnaswamy, S. McFarlane, and E. Ruthazer for comments and suggestions on previous versions of this manuscript, and Brigitte Pié for excellent technical assistance. Single-cell RNA libraries were generated using 10X Genomics droplet-based technology and sequenced at the Genome Québec Innovation Centre in Montréal, Québec. This work was supported by a Canadian Institute for Health Research operating grant.

Competing Interests: The authors declare no competing interests.

\section{References:}

Anand, R., Conroys, W.G., Schoepferll, R., Whiting, P., and LindstromS, J. (1991). Neuronal Nicotinic Acetylcholine Receptors Expressedin Xenopus Oocytes Have a Pentameric Quaternary Structure. J. Biol. Chem. 266, 7.

20 Balice-Gordon, R.J., and Lichtman, J.W. (1994). Long-term synapse loss induced by focal blockade of postsynaptic receptors. Nature 372 .

Becht, E., McInnes, L., Healy, J., Dutertre, C.-A., Kwok, I.W.H., Ng, L.G., Ginhoux, F., and Newell, E.W. (2019). Dimensionality reduction for visualizing single-cell data using UMAP. Nat. Biotechnol. 37, 38-44.

25 Belluzzi, O., Sacchi, O., and Wanke, E. (1985). Identification of delayed potassium and calcium currents in the rat sympathetic neurone under voltage clamp. J. Physiol. 358, 109129.

Bray, N.L., Pimentel, H., Melsted, P., and Pachter, L. (2016). Near-optimal probabilistic RNAseq quantification. Nat. Biotechnol. 34, 525-527.

30 Buffelli, M., Burgess, R.W., Feng, G., Lobe, C.G., Lichtman, J.W., and Sanes, J.R. (2003). Genetic evidence that relative synaptic efficacy biases the outcome of synaptic competition. Nature $424,430-434$.

Bustin, S.A., Benes, V., Garson, J.A., Hellemans, J., Huggett, J., Kubista, M., Mueller, R., Nolan, T., Pfaffl, M.W., Shipley, G.L., et al. (2009). The MIQE Guidelines: Minimum Information for

35 Publication of Quantitative Real-Time PCR Experiments. Clin. Chem. 55, 611-622. 
Butler, A., Hoffman, P., Smibert, P., Papalexi, E., and Satija, R. (2018). Integrating single-cell transcriptomic data across different conditions, technologies, and species. Nat. Biotechnol. 36, 411-420.

Chalazonitis, A., Rice, P.J., and Zigmond, R.E. (1980). Increased ganglionic tyrosine hydroxylase and dopamine-beta-hydroxylase activities following preganglionic nerve stimulation: role of nicotine receptors. J. Pharmacol. Exp. Ther. 213, 139-143.

Chong, Y., Saviuk, N., Pie, B., Basisty, N., Quinn, R.K., Schilling, B., Sonenberg, N., Cooper, E., and Haghighi, A.P. (2018). Removing 4E-BP Enables Synapses to Refine without Postsynaptic Activity. Cell Rep. 23, 11-22.

10 Choo, M., Miyazaki, T., Yamazaki, M., Kawamura, M., Nakazawa, T., Zhang, J., Tanimura, A., Uesaka, N., Watanabe, M., Sakimura, K., et al. (2017). Retrograde BDNF to TrkB signaling promotes synapse elimination in the developing cerebellum. Nat. Commun. 8, 195.

Chung, W.-S., Clarke, L.E., Wang, G.X., Stafford, B.K., Sher, A., Chakraborty, C., Joung, J., Foo, L.C., Thompson, A., Chen, C., et al. (2013). Astrocytes mediate synapse elimination through 15 MEGF10 and MERTK pathways. Nature 504, 394-400.

Cohen-Cory, S. (2002). The developing synapse: construction and modulation of synaptic structures and circuits. Science 298, 770-776.

Cohen-Cory, S., Kidane, A.H., Shirkey, N.J., and Marshak, S. (2010). Brain-derived neurotrophic factor and the development of structural neuronal connectivity. Dev.

20 Neurobiol. 70, 271-288.

Cooper, E., Couturier, S., and Ballivet, M. (1991). Pentameric structure and subunit stoichiometry of a neuronal nicotinic acetylcholine receptor. Nature 350, 235-238.

Davies, A.M. (2009). Extracellular signals regulating sympathetic neuron survival and target innervation during development. Auton. Neurosci. 151, 39-45.

25 Deppmann, C.D., Mihalas, S., Sharma, N., Lonze, B.E., Niebur, E., and Ginty, D.D. (2008). A Model for Neuronal Competition During Development. Science 320, 369-373.

Emmenlauer, M., Ronneberger, O., Ponti, A., Schwarb, P., Griffa, A., Filippi, A., Nitschke, R., Driever, W., and Burkhardt, H. (2009). XuvTools: free, fast and reliable stitching of large 3D datasets. J. Microsc. 233, 42-60.

30 Ernsberger, U., and Rohrer, H. (1999). Development of the cholinergic neurotransmitter phenotype in postganglionic sympathetic neurons. Cell Tissue Res. 297, 339-361.

Flavell, S.W., and Greenberg, M.E. (2008). Signaling Mechanisms Linking Neuronal Activity to Gene Expression and Plasticity of the Nervous System. Annu. Rev. Neurosci. 31, 563-590. 
Forehand, C.J. (1985). Density of somatic innervation on mammalian autonomic ganglion cells is inversely related to dendritic complexity and preganglionic convergence. J. Neurosci. 5, 3403-3408.

Furlan, A., Lübke, M., Adameyko, I., Lallemend, F., and Ernfors, P. (2013). The transcription factor Hmx1 and growth factor receptor activities control sympathetic neurons diversification. EMBO J. 32, 1613-1625.

Furlan, A., La Manno, G., Lübke, M., Häring, M., Abdo, H., Hochgerner, H., Kupari, J., Usoskin, D., Airaksinen, M.S., Oliver, G., et al. (2016). Visceral motor neuron diversity delineates a cellular basis for nipple- and pilo-erection muscle control. Nat. Neurosci. 19, 1331-1340.

10 Furshpan, E.J., Potter, D.D., and Landis, S.C. (1979). On the transmitter repertoire of sympathetic neurons in culture. Harvey Lectures 76, 149-191.

Harrington, A.W., and Ginty, D.D. (2013). Long-distance retrograde neurotrophic factor signalling in neurons. Nat. Rev. Neurosci. 14, 177-187.

Hashimoto, K., Tsujita, M., Miyazaki, T., Kitamura, K., Yamazaki, M., Shin, H.-S., Watanabe, M., 15 Sakimura, K., and Kano, M. (2011). Postsynaptic P/Q-type Ca2+ channel in Purkinje cell mediates synaptic competition and elimination in developing cerebellum. Proc. Natl. Acad. Sci. 108, 9987-9992.

He, T.-C., Zhou, S., Da Costa, L.T., Yu, J., Kinzler, K.W., and Vogelstein, B. (1998). A simplified system for generating recombinant adenoviruses. Proc. Natl. Acad. Sci. 95, 2509-2514.

20 Hill, C.E., Jones, R.S.G., Hirst, G.D.S., and Edwards, F.R. (1991). Development of a functional innervation of the iris dilator muscle by sympathetic nerve fibres in the rat. J. Auton. Nerv. Syst. 32, 21-29.

Hua, J.Y., and Smith, S.J. (2004). Neural activity and the dynamics of central nervous system development. Nat. Neurosci. 7, 327-332.

25 Huang, E.J., and Reichardt, L.F. (2001). Neurotrophins: roles in neuronal development and function. Annu. Rev. Neurosci. 24, 677.

Kano, M., and Hashimoto, K. (2009). Synapse elimination in the central nervous system. Curr. Opin. Neurobiol. 19, 154-161.

Kaplan, D.R., and Miller, F.D. (2000). Neurotrophin signal transduction in the nervous system. Curr. Opin. Neurobiol. 10, 381-391.

Katz, L.C., and Shatz, C.J. (1996). Synaptic activity and the construction of cortical circuits. Science 274, 1133-1138.

Kawata, S., Miyazaki, T., Yamazaki, M., Mikuni, T., Yamasaki, M., Hashimoto, K., Watanabe, M., Sakimura, K., and Kano, M. (2014). Global Scaling Down of Excitatory Postsynaptic 
Responses in Cerebellar Purkinje Cells Impairs Developmental Synapse Elimination. Cell Rep. 8, 1119-1129.

Krishnaswamy, A., and Cooper, E. (2009). An Activity-Dependent Retrograde Signal Induces the Expression of the High-Affinity Choline Transporter in Cholinergic Neurons. Neuron 61, $272-286$.

Laplante, M., and Sabatini, D.M. (2012). mTOR Signaling in Growth Control and Disease. Cell 149, 274-293.

Leslie, J.H., and Nedivi, E. (2011). Activity-regulated genes as mediators of neural circuit plasticity. Prog. Neurobiol. 94, 223-237.

10 Lichtman, J.W., and Colman, H. (2000). Synapse elimination and indelible memory. Neuron 25, 269-278.

Lipton, J.O., and Sahin, M. (2014). The Neurology of mTOR. Neuron 84, 275-291.

Longair, M.H., Baker, D.A., and Armstrong, J.D. (2011). Simple Neurite Tracer: open source software for reconstruction, visualization and analysis of neuronal processes.

15 Bioinformatics 27, 2453-2454.

Lonze, B.E., and Ginty, D.D. (2002). Function and regulation of CREB family transcription factors in the nervous system. Neuron 35, 605-623.

Lorenzetto, E., Caselli, L., Feng, G., Yuan, W., Nerbonne, J.M., Sanes, J.R., and Buffelli, M. (2009). Genetic perturbation of postsynaptic activity regulates synapse elimination in

20 developing cerebellum. Proc. Natl. Acad. Sci. 106, 16475-16480.

Lu, W., Bushong, E.A., Shih, T.P., Ellisman, M.H., and Nicoll, R.A. (2013). The CellAutonomous Role of Excitatory Synaptic Transmission in the Regulation of Neuronal Structure and Function. Neuron 78, 433-439.

Luebke, J.I., and Wright, L.L. (1992). Characterization of superior cervical ganglion neurons 25 that project to the submandibular glands, the eyes, and the pineal gland in rats. Brain Res. $589,1-14$.

McAllister, A.K., Katz, L.C., and Lo, D.C. (1999). Neurotrophins and Synaptic Plasticity. Annu. Rev. Neurosci. 22, 295-318.

McCarthy, D.J., Chen, Y., and Smyth, G.K. (2012). Differential expression analysis of 30 multifactor RNA-Seq experiments with respect to biological variation. Nucleic Acids Res. $40,4288-4297$.

McDonough, J., and Deneris, E. (1997). $\beta 43^{\prime}$ : an enhancer displaying neural-restricted activity is located in the 3 -untranslated exon of the rat nicotinic acetylcholine receptor $\beta 4$ gene. J. Neurosci. 17, 2273-2283. 
Miller, F.D., and Kaplan, D.R. (2003). Signaling mechanisms underlying dendrite formation. Curr. Opin. Neurobiol. 13, 391-398.

Neniskyte, U., and Gross, C.T. (2017). Errant gardeners: glial-cell-dependent synaptic pruning and neurodevelopmental disorders. Nat. Rev. Neurosci. 18, 658-670.

5 Neuhuber, W., and Schrödl, F. (2011). Autonomic control of the eye and the iris. Auton. Neurosci. 165, 67-79.

Park, H., and Poo, M. (2012). Neurotrophin regulation of neural circuit development and function. Nat. Rev. Neurosci. 14, 7-23.

Purves, D., Snider, W.D., and Voyvodic, J.T. (1988). Trophic regulation of nerve cell morphology and innervation in the autonomic nervous system. Nature.

R Core Team (2013). R: A language and environment for statistical computing. R Foundation for Statistical Computing, Vienna, Austria.

Rassadi, S., Krishnaswamy, A., Pie, B., McConnell, R., Jacob, M., and Cooper, E. (2005). A Null Mutation for the 3 Nicotinic Acetylcholine (ACh) Receptor Gene Abolishes Fast Synaptic

15 Activity in Sympathetic Ganglia and Reveals That ACh Output from Developing Preganglionic Terminals Is Regulated in an Activity-Dependent Retrograde Manner. J. Neurosci. 25, 8555-8566.

Rathouz, M., and Berg, D. (1994). Synaptic-type acetylcholine receptors raise intracellular calcium levels in neurons by two mechanisms. J. Neurosci. 14, 6935-6945.

20 Redmond, L. (2008). Translating Neuronal Activity into Dendrite Elaboration: Signaling to the Nucleus. Neurosignals 16, 194-208.

Riccomagno, M.M., and Kolodkin, A.L. (2015). Sculpting Neural Circuits by Axon and Dendrite Pruning. Annu. Rev. Cell Dev. Biol. 31, 779-805.

Robinson, M.D., McCarthy, D.J., and Smyth, G.K. (2010). edgeR: a Bioconductor package for 25 differential expression analysis of digital gene expression data. Bioinformatics 26, 139-140.

RStudio Team (2015). RStudio: Integrated Development for R. RStudio, Inc., Boston, MA.

Schotzinger, R.J., and Landis, S.C. (1990). Acquisition of cholinergic and peptidergic properties by sympathetic innervation of rat sweat glands requires interaction with normal target. Neuron 5, 91-100.

30 Segal, R.A., and Greenberg, M.E. (1996). Intracellular Signaling Pathways Activated by Neuropathic Factors. Annu. Rev. Neurosci. 19, 463-489.

Sheu, S.-H., Tapia, J.C., Tsuriel, S., and Lichtman, J.W. (2017). Similar synapse elimination motifs at successive relays in the same efferent pathway during development in mice. ELife 6, e23193. 
da Silva, S., and Wang, F. (2011). Retrograde neural circuit specification by target-derived neurotrophins and growth factors. Curr. Opin. Neurobiol. 21, 61-67.

Singh, K.K., Park, K.J., Hong, E.J., Kramer, B.M., Greenberg, M.E., Kaplan, D.R., and Miller, F.D. (2008). Developmental axon pruning mediated by BDNF-p75NTR-dependent axon

5 degeneration. Nat. Neurosci. 11, 649-658.

Snider, W.D. (1988). Nerve growth factor enhances dendritic arborization of sympathetic ganglion cells in developing mammals. J. Neurosci. 8, 2628-2634.

Snider, W.D., and Lichtman, J.W. (1996). Are neurotrophins synaptotrophins? Mol. Cell. Neurosci. 7, 433-442.

10 Soneson, C., Love, M.I., and Robinson, M.D. (2016). Differential analyses for RNA-seqtranscript-level estimates improve gene-level inferences. F1000Research 4.

Spitzer, N.C. (2012). Activity-dependent neurotransmitter respecification. Nat. Rev. Neurosci. 13, 94-106.

Stuart, T., Butler, A., Hoffman, P., Hafemeister, C., Papalexi, E., Mauck, W.M., Hao, Y., 15 Stoeckius, M., Smibert, P., and Satija, R. (2019). Comprehensive Integration of Single-Cell Data. Cell 177, 1888-1902.

Tasdemir-Yilmaz, O.E., and Segal, R.A. (2016). There and back again: coordinated transcription, translation and transport in axonal survival and regeneration. Curr. Opin. Neurobiol. 39, 62-68.

20 Taylor, S., Wakem, M., Dijkman, G., Alsarraj, M., and Nguyen, M. (2010). A practical approach to RT-qPCR - publishing data that conform to the MIQE guidelines. Methods 50, S1-S5.

Thompson, W., Kuffler, D.P., and Jansen, J.K.S. (1979). The effect of prolonged, reversible block of nerve impulses on the elimination of polyneuronal innervation of new-born rat skeletal muscle fibers. Neuroscience 4, 271-281.

25 Vernino, S., Rogers, M., Radcliffe, K., and Dani, J. (1994). Quantitative measurement of calcium flux through muscle and neuronal nicotinic acetylcholine receptors. J. Neurosci. 14, 5514-5524.

Voyvodic, J.T. (1989). Peripheral target regulation of dendritic geometry in the rat superior cervical ganglion. J. Neurosci. 9, 1997-2010.

30 Walicke, P.A., Campenot, R.B., and Patterson, P.H. (1977). Determination of transmitter function by neuronal activity. Proc. Natl. Acad. Sci. 74, 5767-5771.

Wilton, D.K., Dissing-Olesen, L., and Stevens, B. (2019). Neuron-Glia Signaling in Synapse Elimination. Annu. Rev. Neurosci. 42, 107-127. 
Wong, R.O.L., and Ghosh, A. (2002). Activity-dependent regulation of dendritic growth and patterning. Nat. Rev. Neurosci. 3, 803-812.

Xu, W., Gelber, S., Orr-Urtreger, A., Armstrong, D., Lewis, R.A., Ou, C.-N., Patrick, J., Role, L., De Biasi, M., and Beaudet, A.L. (1999). Megacystis, mydriasis, and ion channel defect in mice

5 lacking the $\alpha 3$ neuronal nicotinic acetylcholine receptor. Proc. Natl. Acad. Sci. 96, 57465751.

Yamamori, T., Fukada, K., Aebersold, R., Korsching, S., Fann, M., and Patterson, P. (1989). The cholinergic neuronal differentiation factor from heart cells is identical to leukemia inhibitory factor. Science 246, 1412-1416.

10 Yamashita, N., and Kuruvilla, R. (2016). Neurotrophin signaling endosomes: biogenesis, regulation, and functions. Curr. Opin. Neurobiol. 39, 139-145.

Yap, E.-L., and Greenberg, M.E. (2018). Activity-Regulated Transcription: Bridging the Gap between Neural Activity and Behavior. Neuron 100, 330-348.

Yurchenko, E., Friedman, H., Hay, V., Peterson, A., and Piccirillo, C.A. (2007). Ubiquitous

15 expression of mRFP-1 in vivo by site-directed transgenesis. Transgenic Res. 16, 29-40.

Zeng, X., Ye, M., Resch, J.M., Jedrychowski, M.P., Hu, B., Lowell, B.B., Ginty, D.D., and Spiegelman, B.M. (2019). Innervation of thermogenic adipose tissue via a calsyntenin $3 \beta-$ S100b axis. Nature 569, 229-235.

Zhang, L.I., and Poo, M. (2001). Electrical activity and development of neural circuits. Nat.

20 Neurosci. 4, 1207-1214.

Zhang, X., Li, T., Liu, F., Chen, Y., Yao, J., Li, Z., Huang, Y., and Wang, J. (2019). Comparative Analysis of Droplet-Based Ultra-High-Throughput Single-Cell RNA-Seq Systems. Mol. Cell 73, 130-142.e5.

Zweifel, L.S., Kuruvilla, R., and Ginty, D.D. (2005). Functions and mechanisms of retrograde 25 neurotrophin signalling. Nat. Rev. Neurosci. 6, 615-625. 
bioRxiv preprint doi: https://doi.org/10.1101/2020.10.21.349142; this version posted October 22, 2020. The copyright holder for this preprint (which was not certified by peer review) is the author/funder. All rights reserved. No reuse allowed without permission.

A

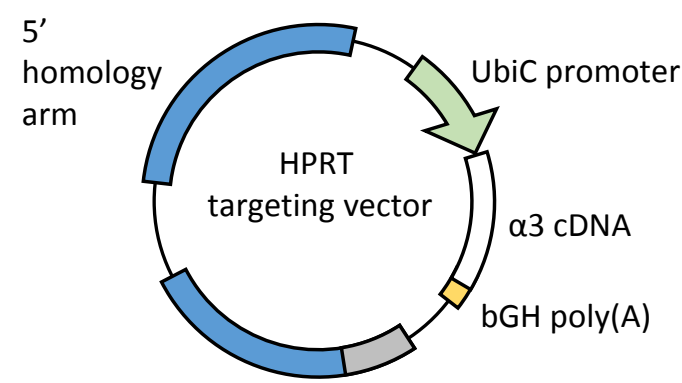

3' homology arm

partial HPRT to

restore function
B

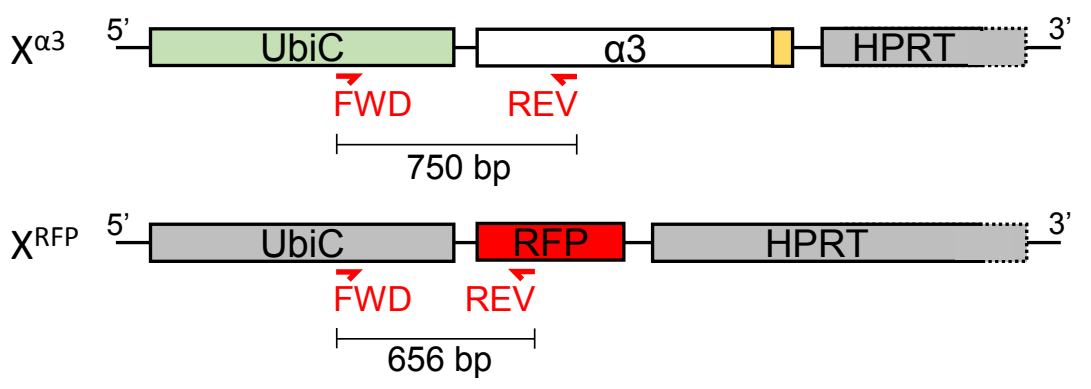

D

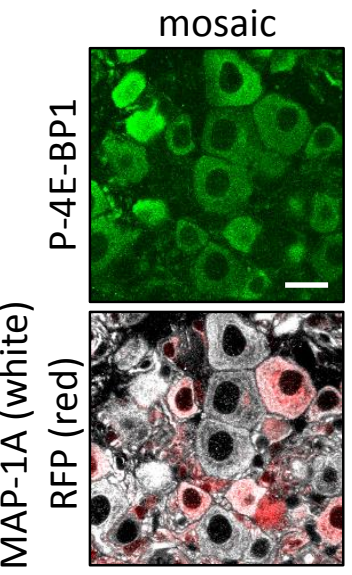

E

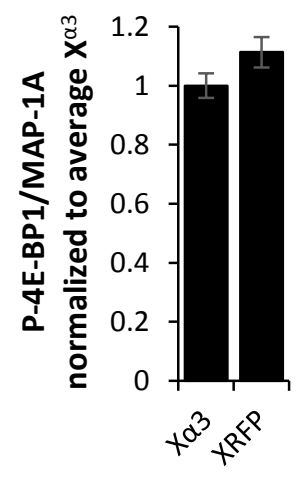

$\mathbf{F}$
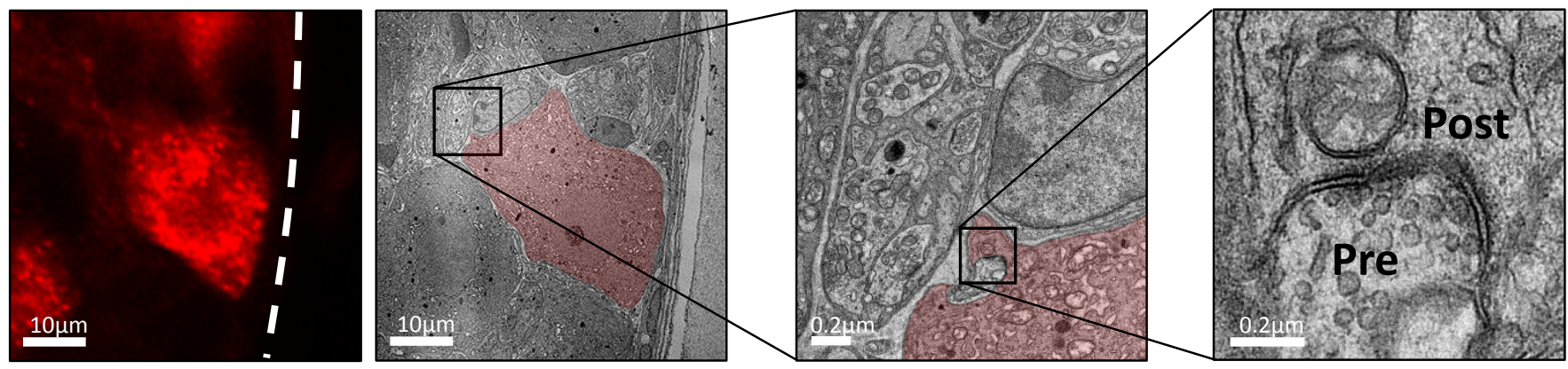


\section{Figure S1. Design of the mosaic mouse model.}

(A) $\alpha 3$ rat cDNA (white) was ligated into a previously modified vector in between the human ubiquitin $\mathrm{C}$ promoter (UbiC; green) and bovine growth hormone polyA site (bGH poly(A); yellow) and recombined in vitro into the HPRT gateway destination vector to generate the targeting vector. Homology arms (blue) direct homologous recombination into the HPRT locus, and partial HPRT (grey) restores HPRT function in HPRT-deficient ES cells for resistance to HAT media (see Materials and Methods).

(B) Diagram shows locations of $\alpha 3$ and mRFP1 genes between the human ubiquitin $C$ promoter (UbiC) and HPRT gene on the X chromosome. Forward (FWD) and reverse (REV)

10 primers used for genotyping are indicated in red with expected amplicon sizes, primer sequences can be found in Materials and Methods.

(C) Relative $\alpha 3$ mRNA expression in SCG normalized to $\alpha 3+/-$ SCG. For $\mathrm{X}^{\alpha 3}, \mathrm{n}=22$ mice; for WT, $n=3$ mice, for $\alpha 3+/-, n=3$ mice; and for $\alpha 3 \mathrm{KO}, \mathrm{n}=2$ mice.

(D) Confocal images showing immunostaining for P-4E-BP1 (green) and MAP-1A (white) in

15 mosaic SCG (RFP expression in red) at P28. Scale bar, $20 \mu \mathrm{m}$.

(E) P-4E-BP1 mean fluorescence intensity per neuron normalized to MAP-1A in $\mathrm{X}^{\alpha 3}$ and $\mathrm{X}^{\mathrm{RFP}}$ neurons at $\mathrm{P} 1, \mathrm{P} 4$ and $\mathrm{P} 28$.

(F) Corresponding images of a $\mathrm{X}^{\mathrm{RFP}}$ neuron viewed at the light microscopy level and at the ultrastructural level (red). Boxed areas were magnified to show presynaptic vesicles and postsynaptic densities. 
bioRxiv preprint doi: https://doi.org/10.1101/2020.10.21.349142; this version posted October 22, 2020. The copyright holder for this preprint (which was not certified by peer review) is the author/funder. All rights reserved. No reuse allowed without permission.

\section{A WT}

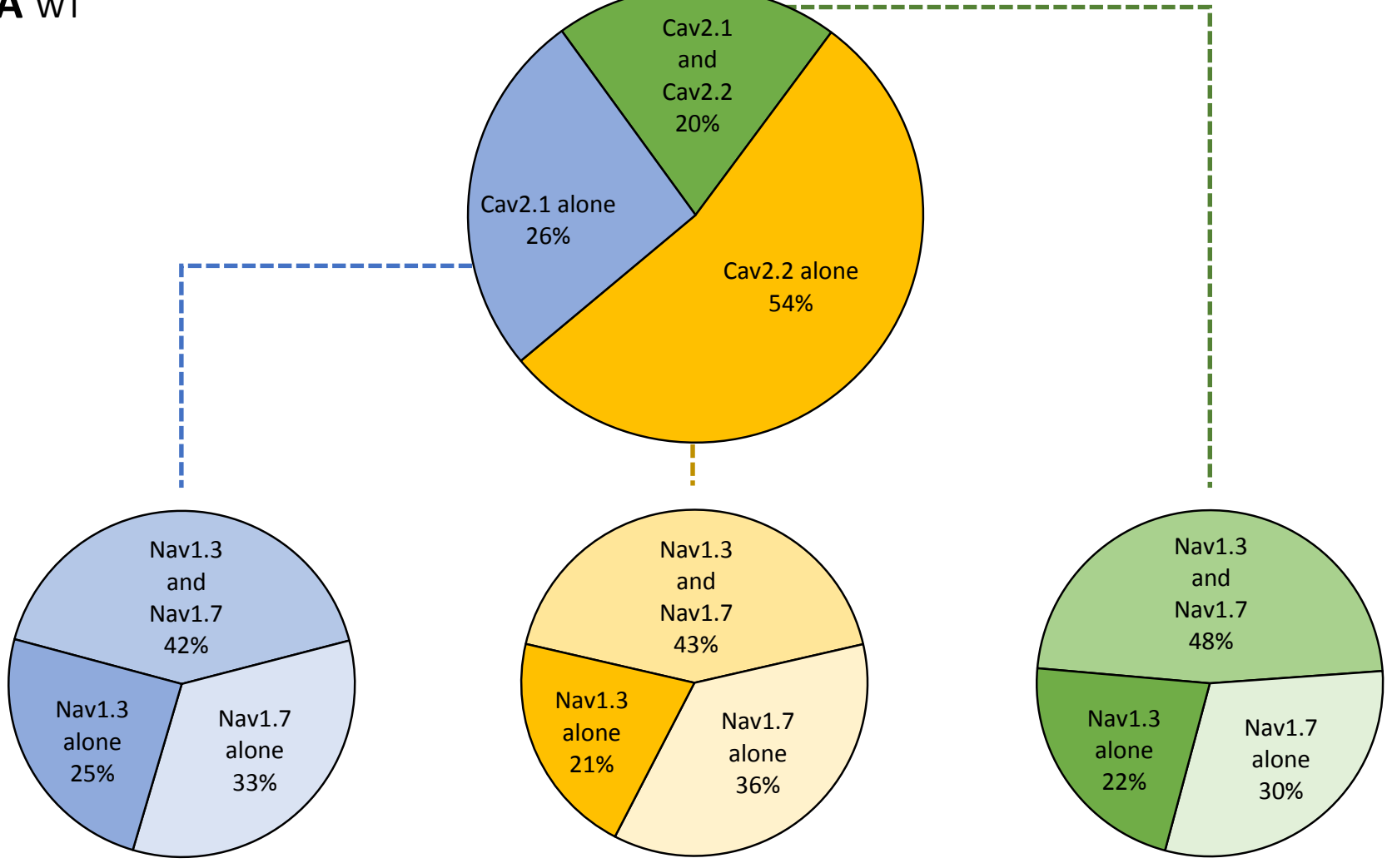

B $\alpha 3$ KO

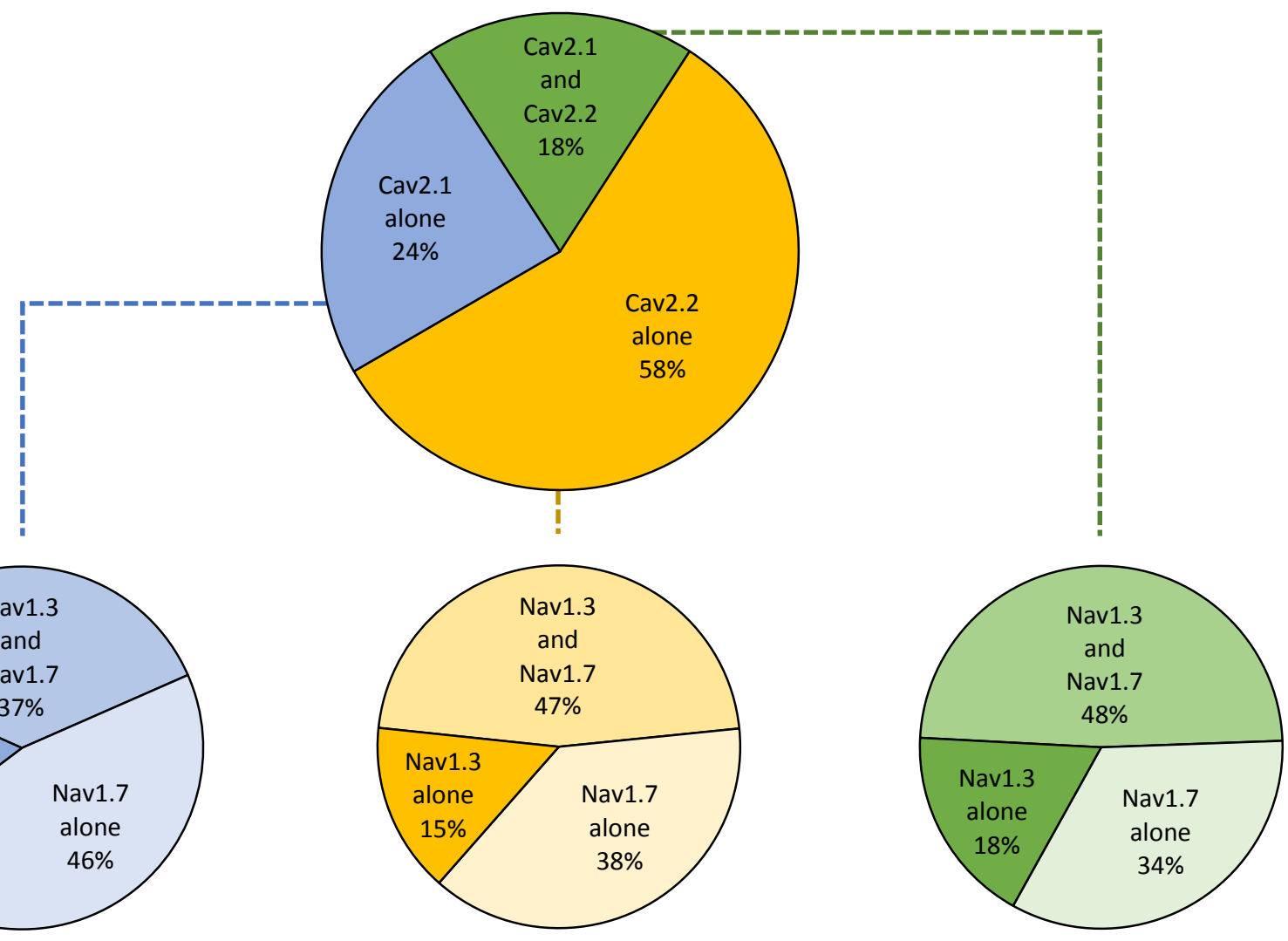


Figure S2. Expression of $\alpha_{1} \mathrm{Ca}_{\mathrm{v}}$ subunit and $\alpha \mathrm{Na}_{\mathrm{v}}$ subunit genes in WT and $\alpha 3 \mathrm{KO}$ neurons.

(A-B) Top: Distribution of neurons that expressed Cacna1a without Cacna1b (Cav 2.1; blue), Cacna1b without Cacna1a (Cav 2.2; yellow), or both (green) in (A) WT SCG and (B) $\alpha 3$ KO

5 SCG.

Bottom: Each of the three $\mathrm{Ca}_{v}$ groups were further broken down according to the distribution of neurons that expressed Scn3a without Scn9a (Na 1.3$)$, Scn9a without Scn3a $\left(\mathrm{Na}_{\mathrm{v}} 1.7\right)$, or both. 


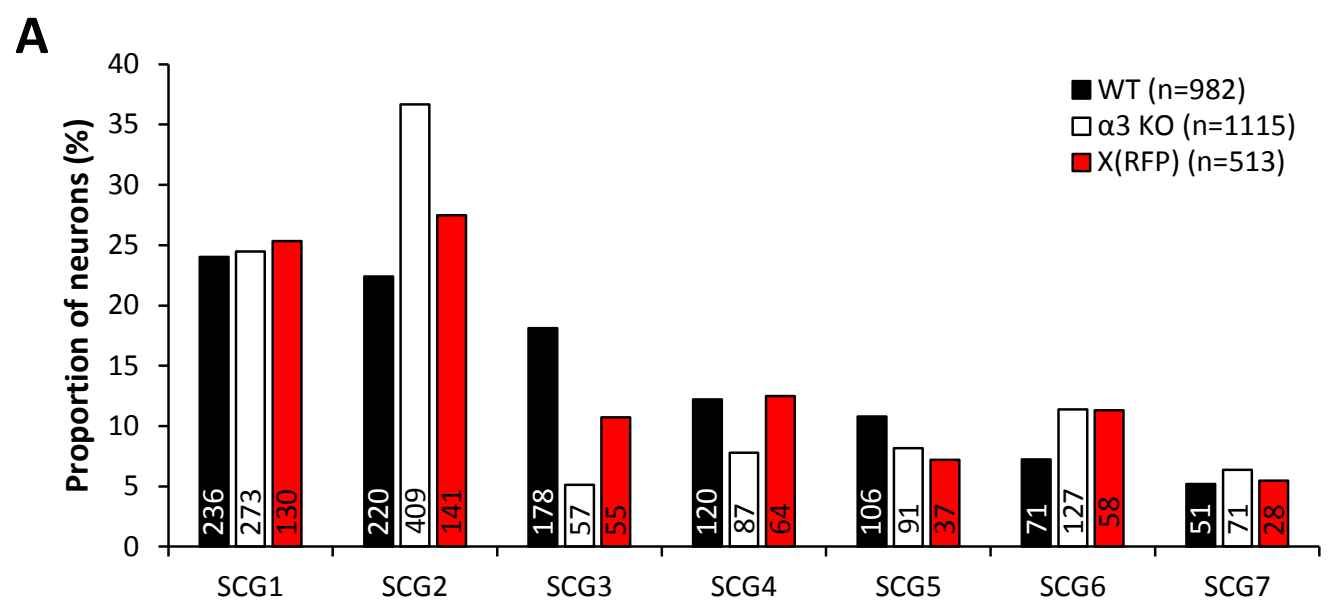


bioRxiv preprint doi: https://doi.org/10.1101/2020.10.21.349142; this version posted October 22, 2020. The copyright holder for this preprint (which was not certified by peer review) is the author/funder. All rights reserved. No reuse allowed without permission.

Figure S3. SCG neurons were clustered into 7 subtypes.

The proportion of WT (black), $\alpha 3 \mathrm{KO}$ (white) and X ${ }^{\mathrm{RFP}}$ (red) SCG neurons categorized into each subtype. 
bioRxiv preprint doi: https://doi.org/10.1101/2020.10.21.349142; this version posted October 22, 2020. The copyright holder for this preprint (which was not certified by peer review) is the author/funder. All rights reserved. No reuse allowed without permission.

A

3

5
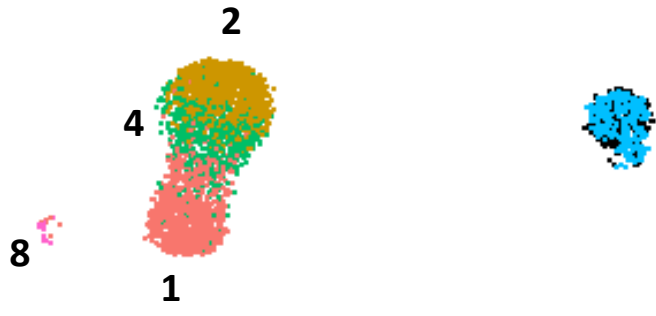

3

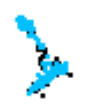

8

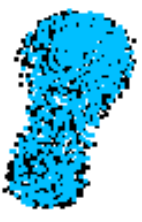

- WT

- $\alpha 3 \mathrm{KO}$ 
Figure S4. Gene expression profiles of non-neuronal cells from WT and $\alpha 3$ KO SCG do not differ significantly.

(A-B) Non neuronal cells from WT (black) and $\alpha 3$ KO (blue) SCG were clustered into 8 subtypes and visualized with UMAPs sorted by (A) subtype and sorted by (B) genotype. 


\section{Supplemental Information titles and legends:}

\section{Table S1. Differentially expressed genes in iris.}

$\log _{2}$ fold change and corresponding $\mathrm{p}$ values for genes identified by RNAseq in iris tissue between $\alpha 3$ KO vs. WT, and between mosaic vs. WT. Genes with low counts were filtered out. Values highlighted in green are not significantly different from $W T\left(\log _{2} \mathrm{FC}<0.585, \mathrm{p}\right.$ value $<0.05$ ).

\section{Table S2. Marker genes for neuronal subtypes in WT SCG.}

Marker genes that define WT SCG subtypes are listed with corresponding average $\ln (\mathrm{x}+1)$ fold change between neurons of a particular SCG subtype compared to the average

10 expression in all other subtypes combined, $\mathrm{p}$ values and Bonferonni adjusted $\mathrm{p}$ values, the proportion of neurons expressing the given gene in that SCG subtype, and the proportion of neurons expressing the given gene in all other subtypes combined.

\section{Table S3. Differentially expressed genes in SCG neurons.}

Genes that are expressed at significantly different levels between WT and $\alpha 3$ KO neurons in

15 at least one SCG subtype are listed. For each SCG subtype, the table contains normalized average expression levels in WT and $\alpha 3 \mathrm{KO}$ neurons, the average $\ln (\mathrm{x}+1)$ fold change between WT and $\alpha 3 \mathrm{KO}$ neurons, and the normalized average expression level in $\mathrm{X}^{\mathrm{RFP}}$ neurons. Values in bold indicate significantly different expression between WT and $\alpha 3$ KO in that subtype, and values in blue indicate genes that are restored towards WT levels in

$20 \quad \mathrm{X}^{\mathrm{RFP}}$ neurons.

\section{Table S4. Marker genes for non-neuronal subtypes in WT SCG.}

Marker genes that define non-neuronal subtypes in WT SCG are listed with corresponding average $\ln (\mathrm{x}+1)$ fold change between cells of a particular SCG subtype compared to the average expression in all other subtypes combined, $p$ values and Bonferonni adjusted $p$

25 values, the proportion of cells expressing the given gene in that SCG subtype, and the proportion of cells expressing the given gene in all other subtypes combined.

\section{Table S5. Differentially expressed genes in SCG non-neuronal cells.}

The table lists genes that are expressed at significantly different levels between nonneuronal cells in WT and $\alpha 3$ KO SCG, with corresponding average $\ln (\mathrm{x}+1)$ fold change between cells of a particular non-neuronal subtype compared to the average expression in all other subtypes combined, $\mathrm{p}$ values and Bonferonni adjusted $\mathrm{p}$ values, the proportion of cells expressing the given gene in that non-neuronal subtype, and the proportion of cells expressing the given gene in all other non-neuronal subtypes combined. 